WP 17_14

\author{
Guido Matias Cortes \\ University of Manchester, UK \\ The Rimini Centre for Economic Analysis, Italy \\ Giovanni Gallipoli \\ University of British Columbia, Canada \\ HCEO, USA \\ The Rimini Centre for Economic Analysis, Italy
}

\title{
The Costs of OCCUPATIONAL Mobility: An Aggregate Analysis
}

Copyright belongs to the author. Small sections of the text, not exceeding three paragraphs, can be used provided proper acknowledgement is given.

The Rimini Centre for Economic Analysis (RCEA) was established in March 2007. RCEA is a private, nonprofit organization dedicated to independent research in Applied and Theoretical Economics and related fields. RCEA organizes seminars and workshops, sponsors a general interest journal The Review of Economic Analysis, and organizes a biennial conference: The Rimini Conference in Economics and Finance (RCEF) . The RCEA has a Canadian branch: The Rimini Centre for Economic Analysis in Canada (RCEACanada). Scientific work contributed by the RCEA Scholars is published in the RCEA Working Papers and Professional Report series.

The views expressed in this paper are those of the authors. No responsibility for them should be attributed to the Rimini Centre for Economic Analysis. 


\title{
The Costs of Occupational Mobility: An Aggregate Analysis
}

\author{
Guido Matias Cortes* \\ University of Manchester and RCEA
}

\author{
Giovanni Gallipoli ${ }^{\dagger}$ \\ University of British Columbia, HCEO and RCEA
}

July 9,2014

\begin{abstract}
We estimate the costs of occupational mobility using a novel approach that relies on aggregate flows of workers across occupations rather than on wage data. The theoretical underpinnings for this approach are derived from a model of occupation choice that delivers a gravity equation linking worker flows to occupation characteristics and to transition costs, which we proxy using task data from the Dictionary of Occupational Titles (DOT). Occupation flow data are constructed from the matched monthly Current Population Survey (CPS) between 1994 and 2012. We find that transition costs vary widely across occupations, are increasing in task distance (the dissimilarity in the mix of tasks performed in the two occupations) and are higher for transitions across broad task categories. However, most of the transition costs are accounted for by general, task-independent entry costs, specific to each destination occupation.
\end{abstract}

JEL Codes: J62, J24.

Keywords: Occupational Mobility; Tasks; Worker Flows; Mobility Costs; Gravity Model.

\footnotetext{
${ }^{*}$ Department of Economics, University of Manchester, Arthur Lewis Building, Oxford Road, Manchester, M13 9PL, UK. E-mail: matias.cortes@manchester.ac.uk. Financial support from CLSRN is gratefully acknowledged. We thank Keith Head, Tomasz Swiecki, Nicole Fortin, David Green, Thomas Lemieux, Vadim Marmer and John Ries for insightful comments and suggestions. Carlos Sanchez provided valuable research assistance.

${ }^{\dagger}$ Vancouver School of Economics, University of British Columbia, 997-1873 East Mall, Vancouver, BC V6T 1Z1, Canada. E-mail: gallipol@mail.ubc.ca
} 


\section{Introduction}

Several contributions to the human capital literature have analyzed the costs associated with different types of employment transitions. Topel (1991) provides evidence that a typical male worker in the United States with 10 years of job tenure loses $25 \%$ of his wage if his job ends exogenously. Other papers have analyzed the extent to which human capital is transferable across jobs. Neal (1995) and Parent (2000) argue that an important component of human capital is industry-specific and, therefore, only lost when a worker switches to a different industry. Meanwhile, Kambourov and Manovskii (2009b) and Sullivan (2010) find evidence that a major component of human capital is occupation-specific.

The goal of this paper is to estimate the costs of occupational mobility within a framework that explicitly accounts for the task content of occupations. As argued by Lazear (2003), Poletaev and Robinson (2008) and Gathmann and Schönberg (2010), occupational transitions differ vastly in the extent of task switching that they entail. In some cases a worker may completely change careers, while other transitions involve only a minor adjustment in the mix of tasks performed. If human capital built in an occupation is task-specific, it should be partially transferable to occupations with a similar set of tasks performed.

A key innovation in this paper, relative to previous literature, is the approach that we take in estimating different layers of transition costs. Specifically, we adopt a framework typical of the trade literature. In that literature, the interest is in estimating barriers to trade using data on flows of goods across countries, and proxies for trade costs that include geographical distance and whether the countries share a common border or a common language, among others. We show that this approach may be adapted to identify the costs associated with occupational mobility by using data on worker flows across occupations, and proxies for mobility costs based on task data.

Previous studies of the costs of job transitions have mainly focused on wage data, particularly on the wage changes experienced by displaced workers when transiting into employment in a new firm, occupation or industry. Using this type of empirical approach, Gathmann and Schönberg (2010) and Poletaev and Robinson (2008) find evidence of the importance of task-specific human capital. In contrast, the empirical approach implied by the gravity framework involves the use of worker flow data, rather than wage data, to estimate the costs of occupational switches. This allows us to use data on all workers (rather than only displaced workers) and to adopt a broad notion of the costs and benefits of an occupational transition which include both pecuniary and non-pecuniary returns.

Relating the flows of workers across occupations to the degree of skill transferability was an idea originally suggested by Shaw (1984). ${ }^{1}$ We explicitly test whether worker flows are related

\footnotetext{
${ }^{1}$ See also Artuc et al. (2010), who identify transition costs across industries based on the responsiveness of worker flows to intersectoral wage differences.
} 
to observable measures of task content and determine how much of the total cost of changing occupations can be attributed to task-related measures. Understanding the costs associated with the reallocation of workers across tasks is particularly relevant in the light of the literature on the polarization of the labor market. This literature suggests that technological change has altered the demand for particular tasks (e.g. Autor et al. (2003), Autor et al. (2006), Goos and Manning (2007)), inducing substantial worker reallocation (Autor and Dorn (2009), Cortes (2014)).

The theoretical setting which underpins our empirical analysis involves a partial equilibrium occupational choice model with perfect information, similar to the static framework used in a different context by Eaton and Kortum (2002). There is a continuum of workers, who differ in terms of observable characteristics, including the occupation which they start the period in. Workers make match-specific productivity (or match quality) draws from a set of extreme value distributions corresponding to each potential occupation. The extreme value assumption may be justified by thinking of workers as receiving a large set of offers from different employers within each occupation, and only considering the highest offer in each occupation. The distribution of 'highest offers' (maxima) across employers within each occupation converges to an extreme value distribution.

Once workers observe their draws, they decide which occupation to work in during the period. There are costs to switching occupations, which depend on the particular occupation that the worker starts in, and the particular occupation that he considers switching to. Given the match-specific productivity draws and taking into account the costs and benefits of mobility, the worker chooses the occupation where he will receive the highest payoff. The workers' optimal switching decisions and the properties of the extreme value distribution lead to a gravity-type equation, which describes how the flow of workers between any occupation pair is related to a set of occupation-specific characteristics and to the cost of switching. ${ }^{2}$

To estimate this gravity equation we use variables that are related to the cost of an occupational switch. Following a growing literature, we characterize occupations through a vector of skill or task characteristics (e.g. Autor, Levy, and Murnane (2003), Ingram and Neumann (2006), Gathmann and Schönberg (2010), Poletaev and Robinson (2008)) using data from the Dictionary of Occupational Titles (DOT). We then construct a measure of distance between occupation pairs, which captures the degree of dissimilarity in the mix of tasks performed in the two occupations. If a considerable share of human capital is lost when a worker experiences a dramatic change in the set of tasks she performs, the costs of occupational mobility should be increasing in task distance. We also allow for a fixed cost of switching across occupations that belong to different major task groups (non-routine

\footnotetext{
${ }^{2}$ In this model occupational mobility is driven both by general occupation-level shocks, as in Kambourov and Manovskii (2009a), and by idiosyncratic match quality draws, as in Gibbons, Katz, Lemieux, and Parent (2005) and Groes, Kircher, and Manovskii (2010).
} 
cognitive, routine cognitive, routine manual or non-routine manual), as there may be costs associated with these switches in excess of what is captured by the distance measure. Finally, we allow for occupation-specific entry costs, which are independent of task content and may vary over time. These entry costs capture institutional barriers faced by potential entrants to an occupation, such as qualification credentials, professional training and union membership requirements.

Using these proxies for occupational mobility costs, we estimate the gravity equation using data on monthly worker flows across 2-digit occupations from the matched monthly Current Population Survey (CPS) from 1994 to 2012. This is a period during which the CPS employed dependent coding techniques, which have been shown to reduce the amount of coding error in occupational transitions (Kambourov and Manovskii (2013), Moscarini and Thomsson (2007)). We focus on job-to-job transitions, exploiting the fact that the data is available at a monthly frequency and that we observe individuals' occupations over consecutive months.

We find that task distance is a significant component of the cost of switching occupations, suggesting an important role for task-specific human capital. An increase of one standard deviation in task distance is estimated to increase the cost of switching occupations by nearly 20 percent. If the switch is to a different major task group, that cost is increased further, between 14 and 58 percentage points, depending on the type of transition. Estimated switching costs across specific occupation pairs are substantial, even when considering those occupation pairs that see fairly high volumes of worker flows.

Through a set of counterfactual experiments we estimate the hypothetical increases in mobility rates that would be observed if transition costs were reduced. For the median occupation in our sample, we find that the hypothetical increase in mobility if task-related costs were removed is approximately 7.4 percentage points. Given that monthly occupation mobility rates in the sample range between $1 \%$ and $10 \%$, this increase is considerable. However, this increase represents only around $13 \%$ of the total increase in mobility that would be observed if we also reduced other costs - namely, the task-independent occupational entry costs - to the lowest observed value in the sample. This implies that there is a substantial amount of heterogeneity in task-independent entry costs across occupations, and the majority of the costs of occupational mobility are attributable to task-independent costs. Occupation-specific access costs are estimated to be particularly large in the most desirable occupations (i.e., those with relatively low outflows). The results are similar when alternative task dimensions from the DOT and from its successor, $\mathrm{O}^{*}$ Net, are considered. The results are also robust when we restrict the analysis to younger workers for whom occupational mobility rates are higher and for whom our model assumptions about the occupational choice process may be more realistic (Neal (1999), Gervais, Jaimovich, Siu, and Yedid-Levi (2013)).

Our findings regarding the large magnitude and heterogeneity of the transition costs across 
occupations are in line with the results of Artuc, Chaudhuri, and McLaren (2010) and DixCarneiro (2014) who, using different identification strategies, find that both the mean and the standard deviation of workers' moving costs across industries are high, amounting to several times average income.

The rest of the paper is organized as follows. Section 2 describes how a gravity model similar to Eaton and Kortum (2002) can be used to study flows of workers across occupations and the costs of occupational mobility. Section 3 describes the empirical strategy and the proxies considered for the costs of switching occupations, as well as the data sources. Section 4 presents the findings of the paper, while Section 5 concludes.

\section{Model}

The economic environment is a variant of that in Eaton and Kortum (2002), modified to account for flows of workers across occupations and the costs of occupational mobility. It involves a static partial equilibrium model with perfect information. All equations in this section hold at any period $t$, so for notational simplicity time subscripts are omitted. We introduce time subscripts when describing the empirical implementation in Section 3.

\subsection{Workers and Occupations}

There is a continuum of homogeneous workers of measure 1 indexed by $i$, and a finite set of occupations given by $j \in\{1,2, \ldots, N\}$ with a large number of employers in each occupation. Workers differ in terms of observable characteristics and initial occupation. A worker's occupation at the beginning of the period is predetermined and indexed by $k$.

Workers select endogenously into occupations in order to maximize their utility payoff. The potential payoff in each occupation is individual-specific and can be interpreted as a total lifetime payoff which includes pecuniary benefits (i.e. wages), as well as non-pecuniary returns related to an individual's preference for each particular occupation. Switching occupations is costly, so if individual $i$ selects into an occupation other than his current occupation $k$ he faces an iceberg cost which is occupation-pair specific. This cost may be related to the pecuniary component of the payoff: for example, switchers may receive lower payoffs in their new occupation due to the fact that they need to learn a new set of tasks and are therefore less productive than incumbents. It may also be related to the non-pecuniary component of the payoff: for example, switchers may have to overcome certain institutional barriers in order to enter into a new occupation, some of which may not necessarily be reflected in their post-switching wages. 


\subsection{Payoffs and Match Quality Draws}

Let the potential payoff from selecting into occupation $j$ for worker $i$ whose initial occupation is $k$ be denoted by $\phi_{j}(i \mid k)$. This payoff is given by:

$$
\phi_{j}(i \mid k)=p_{j} f[X(i)]\left(\frac{z_{j}(i)}{d_{k j}}\right)
$$

$p_{j}$ is a single index subsuming those occupation features which affect all individuals and can be interpreted as a measure of the general attractiveness (in terms of utility payoff) of occupation $j . X(i)$ is a vector of individual characteristics, including variables such as education or overall work experience, which reflect general human capital and change the returns for individual $i$ in all potential occupations. $z_{j}(i)$ is a match-quality shock reflecting how well worker $i$ is matched with occupation $j$ in terms of productivity and preferences. The process by which individuals draw the match-specific component of payoffs is described below. $d_{k j}$ represents the cost of switching between the worker's initial occupation $k$ and the potential occupation $j$. Assume $d_{k k}=1$ (staying in the same occupation is costless) and $d_{k j}>1$ for all $j \neq k$. Intuitively, the cost captures time and efficiency losses associated with learning and adapting to a new occupation.

$\phi_{j}(i \mid k)$ may alternatively be interpreted as the potential wage paid to individual $i$ if she selects into occupation $j$. If each occupation $j$ produces a different final good which has a price given by $p_{j}$ and labor is the only input in production, then Equation (1) would hold as long as wages are equal to the value of the marginal product of labor. ${ }^{3}$ Both interpretations of $\phi_{j}(i \mid k)$ - as a utility payoff or as a wage - are compatible with our empirical strategy, given that our estimation relies only on data on flows of workers across occupations, rather than on direct wage or payoff data. Interpreting $\phi_{j}(i \mid k)$ as a total utility payoff captures the fact that occupational choices are based on both pecuniary and non-pecuniary factors, and on long-run considerations that are not necessarily reflected in current wages.

For each occupation $j$, individuals draw $z_{j}(i)$ from a Fréchet distribution. ${ }^{4}$ One can think of individuals as receiving job offers from several different potential employers in each occupation. The only offer the individuals will consider will be the best offer in each occupation (the one that offers the highest match quality). Thus, the set of 'relevant' offers for each

\footnotetext{
${ }^{3}$ Under this interpretation the logarithm of Equation (1) is:

$$
\ln \phi_{j}(i \mid k)=\ln p_{j}+\ln f[X(i)]-\ln d_{k j}+\ln z_{j}(i)
$$

which is similar to the wage equations commonly specified in the literature, with $\ln p_{j}$ representing an occupation wage premium and $\ln f[X(i)]$ the return to a set of observable characteristics. Here the equation also includes the switching cost $\ln d_{k j}$, and has an error term that is extreme-value distributed, as described below. However this is an equation for potential rather than observed wages so it would not be possible to directly estimate it.

${ }^{4}$ A similar setup is used by Hsieh, Hurst, Jones, and Klenow (2013).
} 
occupation is the collection of maxima across firms for each individual. The distribution of the maxima of a set of draws can converge to one of only three distributions, one of which is Fréchet (type II extreme-value).$^{5}$

The Fréchet distribution has a CDF given by:

$$
z_{j} \sim F_{j}(z)=e^{-T_{j} z^{-\theta}}
$$

The occupation-specific parameter $T_{j}$ governs the location of the distribution. Match quality draws are on average higher in occupations with a larger $T_{j}$. The parameter $\theta$, which is common across occupations, is related to the dispersion of the shocks, with a larger $\theta$ implying less variability.

Individuals sample occupations at the beginning of the period by making a match quality draw for each one, including their starting occupation. They then compare potential payoffs, based on their draws and the transition costs $d_{k j}$, and choose whether to switch occupations, as well as which particular occupation to switch to. ${ }^{6}$ There are no search frictions, and each draw corresponds to a guaranteed job offer from an employer in an occupation, so the individual faces no uncertainty when choosing an occupation.

A crucial assumption, necessary to derive an estimable specification, is that individuals make independent draws from the same set of distributions $F_{j}(z)$, independent of current occupation or individual characteristics. Hence, all individuals have the same ex-ante expected match quality for each occupation $j$. Individuals however make their occupational choices after observing their match quality draws, so their switching decisions will depend on their realized, idiosyncratic draws.

\subsection{Flows of Workers Across Occupations}

For individual $i$ (who starts in occupation $k$ ), the probability that her payoff in occupation $j$ is above some level $\phi$ is given by:

$$
\begin{aligned}
\operatorname{Pr}\left[\phi_{j}(i \mid k)>\phi\right] & =1-F_{j}\left(\frac{\phi d_{k j}}{p_{j} f[X(i)]}\right) \\
& =1-e^{-T_{j} d_{k j}^{-\theta}\left(p_{j} f[X(i)]\right)^{\theta} \phi^{-\theta}}
\end{aligned}
$$

The probability that individual $i$ obtains a payoff below $\phi$ in every occupation other than $j$ is:

\footnotetext{
${ }^{5}$ See Eaton and Kortum (2002), footnote 14, and references therein.

${ }^{6}$ In the current setup, there is no unemployment. The model could be extended to allow workers to have an outside option that guarantees a certain income level, so that if the productivity draws from all occupations are very low for a particular worker, he may choose to remain unemployed for a period.
} 


$$
\begin{aligned}
\operatorname{Pr}\left[\phi_{s}(i \mid k) \leq \phi, \forall s \neq j\right] & =\prod_{s \neq j} F_{s}\left(\frac{\phi d_{k s}}{p_{s} f[X(i)]}\right) \\
& =\prod_{s \neq j} e^{-T_{s} d_{k s}^{-\theta}\left(p_{s} f[X(i)]\right)^{\theta} \phi^{-\theta}}
\end{aligned}
$$

Individual $i$ will optimally choose to switch to occupation $j$, given his current occupation $k$, if $j$ offers him the highest potential payoff among all possible occupations. The probability that this happens is denoted by $\pi_{k j}(i)$ and is given by:

$$
\begin{aligned}
\pi_{k j}(i) & \equiv \operatorname{Pr}\left[\phi_{j}(i \mid k) \geq \max _{s}\left\{\phi_{s}(i \mid k)\right\}\right] \\
& =\int_{0}^{\infty} \operatorname{Pr}\left[\phi_{s}(i \mid k) \leq \phi, \forall s \neq j\right] \cdot d \operatorname{Pr}\left[\phi_{j}(i \mid k) \leq \phi\right] \\
& =\frac{T_{j} d_{k j}^{-\theta} p_{j}^{\theta}}{\sum_{s=1}^{N} T_{s} d_{k s}^{-\theta} p_{s}^{\theta}} .
\end{aligned}
$$

Intuitively, $j$ will be the best choice for individual $i$ whenever $j$ offers her a payoff $\phi$ while all other occupations offer her a payoff below $\phi$. Integrating this over all possible values of $\phi$ gives the probability that $i$ switches from $k$ to $j, \pi_{k j}(i)$. This allows for the possibility that $j=k$, i.e. the optimal choice may involve staying in the current occupation. This probability is not individual-specific, so we can omit the $i$ index.

Taking the ratio of $\pi_{k j}$ and $\pi_{k k}$, based on Equation (5), and using the fact that $d_{k k}=1$, we obtain,

$$
\frac{\pi_{k j}}{\pi_{k k}}=\frac{T_{j} d_{k j}^{-\theta} p_{j}^{\theta}}{T_{k} p_{k}^{\theta}}
$$

Or in logarithms:

$$
\ln \frac{\pi_{k j}}{\pi_{k k}}=\ln T_{j}+\theta \ln p_{j}-\ln T_{k}-\theta \ln p_{k}-\theta \ln d_{k j}
$$

With a large number of individuals in each occupation making independent draws from the match quality distribution, $\pi_{k j}$ will be equal to the fraction of $k$-workers who switch to $j$, that is:

$$
\pi_{k j}=\frac{s w_{k j}}{N_{k}}
$$

where $s w_{k j}$ is the total number of switchers from $k$ to $j$ and $N_{k}$ is the size of occupation $k$ (at the start of the period).

Therefore, Equation (7) can be rewritten in terms of worker flows, leading to a gravity-type 
equation:

$$
\ln \left(\frac{s w_{k j}}{s w_{k k}}\right)_{t}=\ln T_{j, t}+\theta \ln p_{j, t}-\ln T_{k, t}-\theta \ln p_{k, t}-\theta \ln d_{k j, t}
$$

This is the key equation of the model and it holds in every period. Time subscripts are added to explicitly allow for time-variation in the different variables. Equation (9) relates the flows of workers between occupations to a set of occupation-specific characteristics $\left(T_{j, t}, T_{k, t}\right.$, $\left.p_{j, t}, p_{k, t}\right)$, and to the cost of switching $\left(d_{k j, t}\right)$. There are no individual-specific variables such as payoffs or wages in this equation.

\section{Data and Empirical Implementation}

Our objective is to estimate equation (9) in order to quantify the costs of switching between occupations $\left(d_{k j, t}\right)$ and the factors that affect this variable. One such factor is the 'task distance' between occupations $k$ and $j$. As suggested by Gathmann and Schönberg (2010), Poletaev and Robinson (2008) and Robinson (2011), if human capital is task-specific, it should be partly transferable across occupation pairs in which a similar mix of tasks is performed. The cost of switching occupations should therefore be increasing in the degree of dissimilarity, or 'distance', in the task content of the two occupations. ${ }^{7}$

To test the impact of task distance on switching costs, we follow previous literature in characterizing occupations through a vector of skill or task characteristics (e.g. Autor et al. (2003), Ingram and Neumann (2006), Poletaev and Robinson (2008), Peri and Sparber (2009)). We do this using data from the Revised 4th Edition of the Dictionary of Occupational Titles (ICPSR, 1991). The DOT provides precise measures of the different abilities that are required in different occupations, as well as the different work activities performed by job incumbents. The dimensions along which the DOT dataset characterizes occupations include complexity of work, General Education Development (GED), specific vocational preparation requirements, aptitudes, temperaments and physical demands, among others (ICPSR, 1981). The choice of the relevant dimensions to characterize occupations and construct a distance measure is somewhat arbitrary. We choose the three GED variables and the eleven aptitudes from the 1991 DOT as the relevant dimensions for our baseline measure, and test the robustness to different choices in Section 4.5. Table 1 provides examples of the DOT task vectors for four particular occupations. ${ }^{8}$

Following Gathmann and Schönberg (2010), we construct a distance measure across occupation pairs based on angular separation. The distance measure reflects the degree of dissimilarity in the mix of tasks performed in the two occupations, and can be interpreted

\footnotetext{
${ }^{7}$ Task distance here parallels the traditional use of geographic distance in gravity models in the trade literature.

${ }^{8}$ Each DOT dimension is normalized to have mean zero and standard deviation one across the universe of standardized 3-digit occupations from Autor and Dorn (2013). More details are provided in Appendix A.
} 
as an 'intensive margin' description of an occupational transition. Specifically, let $x_{k}^{a}$ be the importance level of dimension $a$ (one of the dimensions described above) in occupation $k$, and $x_{j}^{a}$ the analogous measure for occupation $j$. The angular separation between the task vectors in the two occupations is given by:

$$
\operatorname{AngSep}_{k j}=\frac{\sum_{a=1}^{A}\left(x_{k}^{a} \times x_{j}^{a}\right)}{\left[\sum_{a=1}^{A}\left(x_{k}^{a}\right)^{2} \times \sum_{a=1}^{A}\left(x_{j}^{a}\right)^{2}\right]^{1 / 2}}
$$

where $A$ is the total number of dimensions being considered. AngSep $p_{j j}$ ranges between -1 and 1 , and is increasing in the degree of overlap between the two vectors. We transform this to a distance measure dist $_{k j}$ which ranges between 0 and 1 and is increasing in dissimilarity:

$$
\operatorname{dist}_{k j}=(1 / 2)\left(1-\text { AngSep }_{k j}\right)
$$

In addition to the task distance between occupations, we consider the possibility that there are costs for switching between major task groups. Following the literature (e.g. Acemoglu and Autor (2011)), we group occupations into four broad task groups: non-routine cognitive, routine cognitive, routine manual, and non-routine manual. Appendix Table A.1 provides details on the occupations included in each of these broad groups. We allow for a direct cost of switching between task groups, and we let this cost differ by destination group. More specifically, we define four dummy variables, $\lambda_{k j}^{N C}, \lambda_{k j}^{R C}, \lambda_{k j}^{R M}$ and $\lambda_{k j}^{N M}$, which are equal to one if occupations $k$ and $j$ are in different broad task groups, and destination occupation $j$ is a non-routine cognitive, routine cognitive, routine manual, or non-routine manual occupation, respectively. These dummies reflect costs of switching between task groups that are not fully captured by the distance measure.

We also allow for an overall destination effect $m_{j, t}$, which reflects the general costs of accessing occupation $j$ that are not related to the task content of $j$ or to the characteristics of the source occupation $k$. This may include institutional barriers such as professional qualifications, specific training or other requirements. This cost is allowed to vary over time.

Finally, the unobservable term $\epsilon_{k j, t}$ captures costs of occupational mobility between occupations $k$ and $j$ arising from any other factor. $\epsilon_{k j, t}$ is assumed to be an independently and identically distributed random variable with a standard normal distribution.

We therefore have the following specification for $\ln d_{k j, t}$ :

$$
\ln d_{k j, t}=\beta_{1} d i s t_{k j}+\beta_{2} \lambda_{k j}^{N C}+\beta_{3} \lambda_{k j}^{R C}+\beta_{4} \lambda_{k j}^{R M}+\beta_{5} \lambda_{k j}^{N M}+m_{j, t}+\epsilon_{k j, t}
$$

Substituting equation (12) into the gravity equation (9) and defining $S_{k, t} \equiv \ln T_{k, t}+\theta \ln p_{k, t}$ 
and $D_{j, t} \equiv S_{j, t}-\theta m_{j, t}$, we obtain:

$$
\ln \left(\frac{s w_{k j}}{s w_{k k}}\right)_{t}=D_{j, t}-S_{k, t}-\theta \beta_{1} d i s t_{k j}-\theta \beta_{2} \lambda_{k j}^{N C}-\theta \beta_{3} \lambda_{k j}^{R C}-\theta \beta_{4} \lambda_{k j}^{R M}-\theta \beta_{5} \lambda_{k j}^{N M}-\theta \epsilon_{k j, t}
$$

This equation can be estimated empirically using data on worker flows across occupations.

Note that given the assumptions above, the error term $\theta \epsilon_{k j, t}$ has a normal distribution and is orthogonal to all other regressors.

\subsection{Source and Destination Heterogeneity}

$S_{k, t}$ and $D_{j, t}$ can be captured through time-varying source and destination fixed effects, respectively. An occupation $k$ is estimated to have a high source fixed effect $S_{k, t}$ if outflows from that occupation are relatively low, all else equal (i.e. conditional on the task variables and destination fixed effects). Given that $S_{k, t} \equiv \ln T_{k, t}+\theta \ln p_{k, t}$, a high $S_{k, t}$ may either be due to average match quality in that occupation being high (a high $T_{k, t}$ ) or to the characteristics of that occupation being associated with high utility payoffs (a high $p_{k, t}$ ). In either case our estimates of $S_{k, t}$ will reflect the relative attractiveness of occupation $k$ due to its high average utility payoffs.

Meanwhile, an occupation $j$ is estimated to have a high destination fixed effect $D_{j, t}$ if inflows to that occupation are relatively high, all else equal (i.e. conditional on the task variables and the source fixed effects). Given that $D_{j, t} \equiv S_{j, t}-\theta m_{j, t}$, a high $D_{j, t}$ may be due to occupation $j$ being an attractive occupation to work in, on average, due to its utility payoffs (high $S_{j, t}$ ), or it may be due to occupation $j$ being relatively easy to switch into due to low entry costs (low $m_{j, t}$ ). Given that we can separately identify $S_{k, t}$ and $D_{j, t}$ for all occupations $k$ and $j$ (relative to a base occupation), we can back out the implied value for $-\theta m_{j, t}$ in order to obtain an estimate of this cost for each occupation.

\subsection{Measuring Flows}

We measure flows of workers across occupations using matched monthly data from the Current Population Survey (CPS). The CPS is a monthly survey of approximately 50,000 households conducted by the Bureau of the Census for the Bureau of Labor Statistics. It is the main source of labor market statistics in the United States. We make use of the fact that the CPS is a rotating sample: households included in the CPS survey are sampled for four consecutive months, then leave the sample for eight months, and then return for another four months. Given this sampling structure, up to $75 \%$ of households are potentially matched across consecutive months. In practice, the fraction of households that can be matched is slightly lower (around 70\%), primarily due to the fact that the CPS is an address-based survey, so house- 
holds that move to a new address are not followed. Also, in certain months the CPS made changes to household identifiers, making it impossible to match households across these modifications. ${ }^{9}$ Details about the algorithm used to match individuals across months can be found in Nekarda (2009).

The main advantage of the CPS relative to other longitudinal datasets such as the Panel Study of Income Dynamics (PSID) is its large sample size and the fact that it is explicitly designed to represent the entire US population at each point in time. Another major advantage of the CPS is that, in January 1994, dependent coding techniques were introduced in order to reduce the interview burden and the possibility of occupation and industry misclassification. Specifically, information collected in the previous month's interview began to be imported into the current interview. Instead of having individuals verbally describe their current occupation in each month and having these descriptions coded independently, interviewees were asked whether they still had the same job as in the previous month and, if so, they were automatically assigned the same occupation code as in the previous month. ${ }^{10}$ This method of dependent coding has substantially reduced the amount of spurious transitions across occupations (see Kambourov and Manovskii (2013) and Moscarini and Thomsson (2007)).

To take advantage of the dependent coding techniques, we use data starting in 1994 for our analysis. The most recent period available in our dataset is December 2012. The sample is restricted to adults aged 18 to 65 who are not in farming occupations or in the military.

We perform our analysis at the 2-digit occupation code level. More detailed occupational groupings (i.e. 3-digit codes) provide a level of aggregation that is too fine to observe significant flows of workers across particular occupation pairs. Meanwhile, a higher level of aggregation (1-digit level) creates groups that are too coarsely grouped together. Our 2-digit occupations are an aggregation of the harmonized occupation codes from Autor and Dorn (2013), which are adapted from Meyer and Osborne (2005). The full universe of occupations is listed in Appendix Table A.1. ${ }^{11}$ Appendix A provides details on the procedure followed to merge the CPS and the DOT data.

Using 2-digit occupation codes for matched individuals who are observed across consecutive months, we construct monthly flows of workers across occupation pairs. The flow of job-to-job switchers from occupation $k$ to occupation $j$ in period $t\left(s w_{k j, t}\right)$ is defined as the number of respondents (weighted using CPS sample weights) who are observed in occupation $k$ in month $t$ and in occupation $j$ in month $t+1$. To reduce noise, these monthly flows are aggregated at an annual level.

\footnotetext{
${ }^{9}$ This affects the period between June and September of 1995.

${ }^{10}$ See http://www. census.gov/cps/methodology/collecting.html.

${ }^{11}$ Note that potential discontinuities induced in the occupational categories by the changes in the occupation coding system used by the CPS in 2003 and 2011 are not of concern for the purposes of this paper as the inclusion of time-varying occupation fixed effects implies that identification is obtained solely from variation across occupation pairs in worker flows at a given point in time.
} 


\section{Results}

\subsection{Gravity Equation Estimation}

This section presents the results of the estimation of equation (13) using CPS data on worker flows and the proxies for mobility costs described above. One issue that we need to address is the fact that there are occupation pairs for which flows are zero in specific years. This occurs for approximately $12 \%$ of our occupation pair-year observations. ${ }^{12}$

We deal with the issue of zero-flows in several ways. Column (1) of Table 2 shows the results from the estimation of (13) when observations with zero flows are dropped from the sample. In Column (2), we replace the zeros with the smallest value observed in the sample for the left-hand-side variable in equation (13), and estimate the regression using OLS. Finally, in Column (3) the same replacement of zeros is done as in Column (2) but, following Eaton and Kortum (2001), a Tobit-style regression is estimated instead of using OLS. ${ }^{13}$ All specifications include source and destination occupation fixed effects interacted with year dummies.

The table shows that the effect of task distance on worker flows is negative and significant, suggesting that task distance is an important component of the cost of occupational mobility. The estimate in Column (3) implies that, all else equal, a one standard deviation increase in distance leads to a $57 \%$ fall in the ratio of switchers to stayers. Meanwhile, the negative and significant coefficient estimates on the task switching dummies imply that switching into a different broad task group is costly, and more so when switching towards routine manual occupations. ${ }^{14}$

As can be seen from equation (13), the estimated coefficients presented in the table correspond to $-\theta \beta$. This means that the findings discussed so far, such as the fact that higher distances are associated with lower flows of workers, could be driven either by high-distance switches being very costly (i.e. a high $\beta$ ) or by match quality shocks having a low level of dispersion (i.e. a high $\theta$ ). We disentangle these two components in Section 4.3.

\subsection{Occupation Access Costs}

The estimated source and destination occupation fixed effects are also of interest. As discussed above, the estimates of $S_{j, t}$ convey information about the relative attractiveness of occupation $j$ in year $t$, while the estimates of $-\theta m_{j, t}$ convey information on the general non-task related costs to enter into occupation $j$ in year $t$. We make the normalizations $S_{2, t}=0 \forall t$ and $m_{2, t}=0 \forall t$ for occupation code 2, "Executives, administrators and managers". ${ }^{15}$ Therefore

\footnotetext{
${ }^{12}$ The issue of zeros in gravity equations has been discussed in the trade literature; see Head and Mayer (2013) for an overview.

${ }^{13}$ See Head and Mayer (2013) for a discussion of the advantages of using this method.

${ }^{14}$ Appendix Figure A.1 illustrates the goodness of fit of the specification in Column (3) by plotting the fitted values of the regression against their true values.

${ }^{15}$ This implies assuming $T_{2, t}=1 \forall t$ and $p_{2, t}=1 \forall t$.
} 
the estimates of the attractiveness and the task costs associated with different occupations should be interpreted as being relative to this base category.

Figure 1 plots estimates of $S_{j}$ (on the x-axis) and $-\theta m_{j}$ (on the y-axis) for each occupation $j$ in the year 2012 obtained from the Tobit-type specification in Column (3) of Table 2. Each circle represents a 2-digit occupation, with the size of the circle representing the size of the occupation in 2012. The numbers within each circle represent the 2-digit occupation code as defined in Appendix Table A.1. The figure shows that attractive occupations (those with high values of $S_{j}$ ) tend to exhibit high entry costs (a high $-\theta m_{j}$ in absolute value), whereas relatively unattractive occupations tend to exhibit relatively low entry costs. "Health assessment and treating occupations" (occupation code 8) is an example of an occupation that has a high estimated $S_{j}$, and is therefore an attractive occupation, but also has a relatively high value of $\theta m_{j}$, meaning that it is generally a difficult (costly) occupation to get into, conditional on the task-related barriers. On the other end of the spectrum, "other administrative support occupations, including clerical" (occupation code 25) is an example of an occupation with relatively low entry costs (low $\theta m_{j}$ ), which is not particularly attractive (low $S_{j}$ ). The ranking across occupations is quite stable over time. Note also that the occupations in the southeastern part of the graph - those which are highly desirable but difficult to access - tend to be populated by relatively small numbers of workers.

\subsection{Match Quality Dispersion or Switching Costs? Estimating $\theta$}

As discussed above, the effect of the task variables on the observed worker flows across occupations depends on the effect of these variables on the transition costs but also on the dispersion of the match quality shocks. Specifically, as is clear from Equation (13), the coefficients obtained from the estimation of the gravity equation correspond to $-\theta \beta$. In order to disentangle these two components, and to obtain an estimate of the costs of switching across occupations, it is necessary to obtain an estimate of $\theta$, the dispersion of the match quality shocks. For this purpose we take advantage of the properties of the extreme value distribution, which lead to a simple relationship between the distribution of payoffs predicted by the model and the parameter of interest $\theta$.

The extreme value distribution in Equation (2) has mean $T_{j}^{1 / \theta} \Gamma(1-1 / \theta)$, where $\Gamma$ is the Gamma function. Its logarithm has a Gumbel distribution, with standard deviation equal to $\pi /(\theta \sqrt{6}) \cdot{ }^{16}$

Note that the (ex-post) payoff for an individual starting in occupation $k, \phi(i \mid k)$, is also drawn from an extreme value distribution. Specifically, the probability that an individual

\footnotetext{
${ }^{16}$ The Gumbel distribution has a CDF given by: $F(x)=\exp \left(-e^{-(x-\mu) / \beta}\right)$, with standard deviation $(\pi \beta) / \sqrt{6}$. In the case of the logarithm of the productivity draws from the extreme value distribution in Equation (2), we have that: $\operatorname{Pr}\left(\ln z_{j}(i) \leq z\right)=\operatorname{Pr}\left(z_{j}(i) \leq e^{z}\right)=F_{j}\left(e^{z}\right)=\exp \left(-T_{j} e^{-\theta z}\right)$, which is a Gumbel distribution with standard deviation $\pi /(\theta \sqrt{6})$.
} 
ends up with a payoff below or equal to $\phi$ is equal to the probability that his potential payoff in all possible occupations is below or equal to $\phi$. That is,

$$
\begin{aligned}
\operatorname{Pr}[\phi(i \mid k) \leq \phi] & =\operatorname{Pr}\left[\phi_{j}(i \mid k) \leq \phi \forall j\right] \\
& =\prod_{j=1}^{N} F_{j}\left(\frac{\phi d_{k j}}{p_{j} f[X(i)]}\right) \\
& =e^{-\left(\sum_{j=1}^{N} T_{j} d_{k j}^{-\theta}\left(p_{j} f[X(i)]\right)^{\theta}\right) \phi^{-\theta}}
\end{aligned}
$$

This is an extreme value distribution with mean $\left[\sum_{j=1}^{N} T_{j} d_{k j}^{-\theta}\left(p_{j} f[X(i)]\right)^{\theta}\right]^{(1 / \theta)} \Gamma(1-1 / \theta)$. Its logarithm has standard deviation $\pi /(\theta \sqrt{6}) .{ }^{17}$

Therefore, for any set of individuals starting in occupation $k$ with common demographic characteristics $X(i)$, we have that $\sigma_{k}^{x}=\pi /(\theta \sqrt{6})$, where $\sigma_{k}^{x}$ denotes the standard deviation of ex-post (log) payoffs within the group. If we use wages as a proxy for total payoffs, this implies that, within the context of the model, increases in within-group wage inequality are related to increases in the dispersion of the distribution of match quality within each occupation (i.e. falls in $\theta$ ).

If we consider the entire set of individuals starting in occupation $k$ (not conditional on demographics), the standard deviation of their ex-post log payoffs will be at least as large as the standard deviation conditional on $X(i)$, due to the heterogeneity in their demographic characteristics. This implies that $\sigma_{k} \geq \pi /(\theta \sqrt{6})$, and therefore $\theta \geq \pi /\left(\sigma_{k} \sqrt{6}\right)$, where $\sigma_{k}$ is the standard deviation of log payoffs for the entire set of individuals starting the period in occupation $k$.

Using wages as a proxy for payoffs, we can obtain a lower-bound estimate of $\theta$ from the data by calculating $\underline{\theta}=\pi /\left(\sigma_{k} \sqrt{6}\right)$, where $\sigma_{k}$ is the standard deviation of log wages among all individuals starting the period in occupation $k$. This can be computed for each month in the sample using information on the distribution of wages in month $t$ for workers with a common occupation $k$ in month $t-1 .^{18}$

In order to obtain a more precise estimate of $\theta$, we also estimate the standard deviation conditioning on demographic characteristics. In particular, we focus on young workers aged 25 to 30 . As they are at the start of their working life, it is reasonable to expect lower heterogeneity in terms of the characteristics that determine their wages. We therefore compute

\footnotetext{
${ }^{17}$ From the previous footnote the standard deviation of the logarithm of productivity does not depend on $T_{j}$. In the case of the distribution of log payoffs, $T_{j}$ would be replaced by $\left(\sum_{j=1}^{N} T_{j} d_{k j}^{-\theta}\left(p_{j} f[X(i)]\right)^{\theta}\right)$. The standard deviation remains independent of this multiplicative constant.

${ }^{18}$ Wage data is available in the CPS for workers in the Outgoing Rotation Groups (fourth and eighth month in the sample). We follow the procedure in Lemieux (2006) to generate hourly wages and to trim extreme values of wages and adjust top-coded earnings.
} 
estimates of $\theta=\pi /\left(\sigma_{k}^{x} \sqrt{6}\right)$ based on the standard deviation of wages for people aged 25 to 30 , by initial occupation and by gender.

Figure A.2 in the Appendix displays histograms of the estimated values of $\underline{\theta}$ and $\theta$, using occupation-month bins with at least 100 observations for $\underline{\theta}$, and occupation-gender-month bins with at least 15 observations for $\theta$. Table 3 presents the corresponding summary statistics. The median estimate of $\theta$ (based on the demographic-specific dispersions) is 3.23 . In the next subsection we use this estimate of $\theta$ to calculate implied mobility costs and perform counterfactual experiments. We discuss the robustness of the results to other assumptions about the value of $\theta$ in Section 4.5.

\subsection{Mobility Costs}

In Table 4, we use the estimate of $\theta=3.23$ to compute the effect of different task variables on the iceberg transition cost $d_{k j}$. The first three columns of Table 4 show, for each of the specifications in Table 2, the estimated marginal effects $\widehat{\beta}$ of each of the variables on the logarithm of the transition cost $\left(\ln d_{k j}\right)$. The next three columns compute the implied percentage effect on $d_{k j}$ from a one standard deviation change in distance, and from a change from 0 to 1 for each of the task switching dummy variables. The results show that the impact of task distance on the cost of switching is substantial. For example, based on the implied coefficients from the Tobit-type specification, Column (6) shows that if distance increases by one standard deviation, the cost of switching occupations increases by nearly $20 \%$, all else equal. Meanwhile, the switching cost is increased if the switch involves a transition into a different task group. These additional costs range from $14 \%$ for transitions into routine cognitive occupations, to $58 \%$ for transitions into routine manual jobs.

\section{Decomposing Mobility Costs}

Next we calculate the estimated transition cost $d_{k j, t}$ for specific occupation pairs based on Equation (12). ${ }^{19}$ We calculate this in three steps. First, we calculate the cost solely attributable to task distance:

$$
\ln d_{k j}^{d i s t}=\widehat{\beta}_{1} d i s t_{k j}
$$

We then add the cost attributable to switching between broad task groups, in order to obtain the total cost associated with the task variables:

$$
\ln d_{k j}^{\text {tasks }}=\widehat{\beta}_{1} d i s t_{k j}+\widehat{\beta}_{2} \lambda_{k j}^{N C}+\widehat{\beta}_{3} \lambda_{k j}^{R C}+\widehat{\beta}_{4} \lambda_{k j}^{R M}+\widehat{\beta}_{5} \lambda_{k j}^{N M}
$$

Finally, we also calculate the full estimated transition cost considering all costs, including

\footnotetext{
${ }^{19}$ We use the results from the Tobit-type specification in Column (3) of Table 2.
} 
the fixed destination entry cost:

$$
\ln d_{k j, t}^{\text {all }}=\widehat{\beta}_{1} d i s t_{k j}+\widehat{\beta}_{2} \lambda_{k j}^{N C}+\widehat{\beta}_{3} \lambda_{k j}^{R C}+\widehat{\beta}_{4} \lambda_{k j}^{R M}+\widehat{\beta}_{5} \lambda_{k j}^{N M}+\widehat{m}_{j, t}
$$

Table 5 shows estimates of these three layers of costs for a selected number of occupation pairs in the year 2012. ${ }^{20}$ The top half of the table lists occupation pairs that exhibit the lowest overall transition costs, while the bottom half presents the occupation pairs for which we estimate the highest transition costs. All the low-cost transitions have a low task distance and do not entail switching between broad task categories. They are also transitions into occupations with relatively low entry costs. Yet, even for such transitions estimated costs remain fairly large. Recall from Equation (1) in the model that $d_{k j, t}$ represents an iceberg cost which reduces the payoff to a worker who switches occupations. For example, the estimated cost of 1.020 associated with the task costs for transitions between "teachers, except college and university" and "executives, administrators and managers" implies that a switcher's payoff would be $2 \%$ higher if there were no costs associated with the task content of occupations (put differently, the utility payoff for an incumbent in the occupation with identical characteristics would be $2 \%$ higher). Overall, the payoff to a worker switching between these two occupations would be almost 3 times higher if all mobility costs were removed. Estimated switching costs are therefore substantial, even across occupations that see relatively high volumes of flows.

Transitions between occupation pairs at the bottom of Table 5 are the most costly. These transitions involve a high task distance, a transition into a different broad task group, and a transition into occupations with high task-independent entry costs (lawyers and judges). Estimated transition costs are in fact prohibitively high and in practice we observe essentially no transitions between these occupations.

As a simple characterization of the relative importance of task variables, we compute the size of the iceberg cost associated with the task variables relative to the overall estimated iceberg cost. That is, $\left(d_{k j, t}^{d i s t}-1\right) /\left(d_{k j, t}^{\text {all }}-1\right)$ for the case of task distance, and $\left(d_{k j, t}^{\text {task }}-\right.$ $1) /\left(d_{k j, t}^{\text {all }}-1\right)$ for all task-related costs. Table 6 presents summary statistics for these ratios across all occupation pair-year cells. For the median observation, task-related costs account for approximately $6 \%$ of the total costs. For 1 in 10 occupation pair-year cells, task-related costs account for more than $13 \%$ of all costs.

\section{Counterfactual Changes in Mobility Rates}

An alternative way to measure the magnitude of the estimated transition costs is by calculating counterfactual occupation mobility rates if the transition costs were reduced. Column (1) of Table 7 shows the observed mobility rates towards other occupations for a number of 2-digit

\footnotetext{
${ }^{20}$ We include the constant from the Tobit regression (divided by the estimate of $\theta$ ) in the estimated total cost, as we think of this as a base cost that applies to all transitions and is therefore part of $\widehat{m}_{j, t}$ for all $j$.
} 
source occupations in the year 2012 (i.e. the total number of switchers as a fraction of the total number of workers in each occupation). The top half of the table includes occupations with the lowest observed outflows (between $2 \%$ and $4 \%$ of workers are observed to switch out at a monthly frequency), while the bottom half of the table includes the occupations with the highest outflows (over 5.5\%). The final row shows aggregate occupational mobility across 2-digit occupations. Column (2) presents fitted outflows, based on the estimation of the gravity equation.

Column (3) shows the estimated counterfactual mobility rates that would be observed if the switching costs associated with task distance were eliminated. The mobility rates in Column (3) are higher than the fitted values in Column (2), and in most cases also higher than the observed values in Column (1). As one would expect, the increases are particularly large for occupations that are very "remote", in the sense that they have large task distances relative to most other occupations. An example of this type of remote occupation is "freight, stock and material handlers" where removing task distance alone increases occupational mobility rates from $8.4 \%$ to $14 \% .^{21}$

Column (4) displays the counterfactual mobility rates if one also removes costs associated with transitions across broad task categories. This induces further increases in mobility rates. Overall, for three quarters of the occupation-year cells in our sample, counterfactual mobility rates increase by at least 5 percentage points (relative to the fitted values) when all task costs are removed. For $10 \%$ of the occupation-year cells, mobility rates increase by more than 12 percentage points. The increase for the median occupation in our sample is of 7.4 percentage points. This change is substantial. It is approximately equal to the difference between the mobility rates for helpers in construction and production occupations (the occupation with the highest mobility rates) and those for lawyers and judges (the occupation with the lowest mobility rate). Meanwhile, the counterfactual increase in aggregate mobility is even larger, at around 11 percentage points.

Column (5) calculates the counterfactual mobility rates that would be observed if, in addition to removing task-related costs, occupation-specific entry costs $m_{j, t}$ are reduced to the lowest observed value in the sample. Clearly these task-independent entry costs are very important, as the counterfactual mobility rates in Column (5) are substantially larger than in Column (4).

The results in Column (5) provide a useful benchmark in order to assess the relative importance of task-related costs relative to general task-independent entry costs. Specifically, we compute this relative importance by comparing the increase in the mobility rates that occur when the task-related costs are removed versus the total increase that occurs when

\footnotetext{
${ }^{21}$ Note that the measure of task distance observed across the two most similar occupations in our sample is close to zero, so performing an alternative experiment where we reduce distance to the smallest empirically observed value in the sample (instead of completely removing distance costs) yields essentially the same results.
} 
task-independent entry costs are also reduced to their minimum. Table 8 presents some summary statistics for these relative changes using all occupation-year observations. For the median occupation, task-related costs account for around $13 \%$ of the counterfactual mobility increase. For more than $25 \%$ of the occupation-year cells, task-related costs account for at least $15 \%$ and up to $24 \%$ of total costs.

Finally, in Column (6) of Table 7 we calculate counterfactual mobility rates if there were no transition costs at all (i.e. no task-related costs as well as no occupation-specific entry costs $m_{j, t}$ ). This is of course not a realistic scenario and as the results show, mobility rates in this case would be unreasonably high. ${ }^{22}$

\subsection{Robustness checks}

To test the robustness of the results we consider a number of alternative dimensions for the construction of task distance. First, we add additional dimensions from the 1991 Dictionary of Occupational Titles to our task vector and to the construction of the distance measure. The additional DOT dimensions are listed in Appendix Table A.2. The results from the estimation of the gravity equation when these additional dimensions are included are presented in Appendix Table A.5. The results for the counterfactual experiments analogous to those in Table 8 are presented in Columns (1) and (2) of Table 9. The fraction of the transition costs that can be attributed to the task variables is slightly higher using this distance measure.

Next, we consider alternative task characterizations which are based on more recent data from $\mathrm{O}^{*} \mathrm{Net}$, the successor to the DOT. ${ }^{23}$ We consider two subsets of data from $\mathrm{O}^{*}$ Net Version 14.0 (2009): Work Activities and Skills. The full set of work activities and skills from O*Net are listed in Appendix Tables A.3 and A.4. The results from the counterfactual experiments using work activities as the dimensions included in the construction of task distance are presented in Columns (3) and (4) of Table 9, while Columns (5) and (6) present the results when the skill dimensions are used. The results are similar, with task distance accounting for around $10 \%$ of transition costs for the median occupation, and costs associated with transitions across broad task groups accounting for an additional 6 to 8 percentage points.

Finally, we allow for a non-linear effect of task distance on the cost of switching occupations, using our benchmark distance measure, by including a cubic function of distance in

\footnotetext{
${ }^{22}$ Note that a similar result applies in the trade literature, where counterfactual results for a world with no trade costs imply substantially higher levels of trade than what is observed in reality (Eaton and Kortum, 2002). In fact, in a world with no trade costs the share of a country's expenditure on its own goods would be proportional to its relative weight in the world economy. Analogously, here, the fraction of non-switchers in the counterfactual with no transition costs would be proportional to the source occupation's relative overall attractiveness within the universe of occupations, specifically: $\frac{T_{k} p_{k}^{\theta}}{\sum_{j} T_{j} p_{j}^{\theta}}$. Given that we have a total of 37 occupations, this term would be equal to 0.027 if all occupations had the same $T_{j}$ and $p_{j}$. In our sample, it ranges between 0.004 and 0.383 .

${ }^{23}$ We thank Nicole Fortin for providing us a crosswalk between O*Net occupation codes and occupation codes from the 1980/1990 Census occupation coding systems.
} 
our gravity equation estimation. This also does not alter the results from the counterfactual experiments, presented in Columns (7) and (8) of Table 9: task-related barriers account for around $14 \%$ of transition costs for the median occupation.

We also check the robustness of the results to alternative assumptions about the value of $\theta$. Assuming a higher value for this parameter implies attributing a larger role to the dispersion of match-specific draws, and a smaller role for transition costs in generating the observed worker flows across occupations. Appendix Tables A.6 and A.7 reproduce the results from Tables 4 and 5 under the assumption that $\theta=4.29$, a relatively high potential value of $\theta$ based on the findings in Table 3. As mentioned, the higher assumed value of $\theta$ reduces the estimated size of the transition costs and the marginal effects of the task variables, but the changes it induces in the estimated costs associated with the task variables are not very large.

Our final robustness check involves estimating the model for a sample of younger workers. Our model assumes that individuals make productivity draws for all occupations and make occupational switching decisions based on those draws. Results from previous literature, such as Neal (1999) and Gervais et al. (2013), suggest that this assumption is more likely to hold for younger workers who are at the start of their careers and are unsure about how well they will be matched to different types of jobs. The data in fact shows that younger workers have higher rates of occupational mobility (Kambourov and Manovskii (2008), Gervais et al. (2013)). We estimate our gravity equation using data on worker flows across occupations using only individuals aged 18 to 35 . The results are quite consistent with our findings for the full sample. Table 10 presents the results for the sample of younger workers for the counterfactual experiments analogous to those in Table 8. Although there is more dispersion in the estimated role of task content across occupations, the effects for the median occupation are very similar to those estimated from the full sample.

\section{Conclusion}

We quantify the costs of occupational mobility using a new approach which relies on data about workers' flows across occupations, rather than on wage data. This approach circumvents the potentially confounding effects embedded in the observed wage changes for switchers and allows us to estimate the costs that workers would face if they chose to switch occupations. These are the costs that limit mobility, and they are not equal to the costs that are actually incurred by workers who decide to make a switch. We posit an occupation choice model which maps into a gravity specification linking workers' flows across occupations, occupation characteristics and the implicit transition costs faced by workers. In the model, workers draw match quality shocks from a set of extreme value distributions for each potential occupation, and choose optimally which occupation to work in, based on their draws, the general attractiveness of alternative occupations and the costs of transiting out of their current occupation. 
The empirical implementation highlights the role of task distance (the degree of dissimilarity in the mix of task requirements) for the cost of switching occupations. This variable is found to play an important role in determining occupation mobility costs. Raising task distance by one standard deviation increases the cost of switching occupations by almost $20 \%$ in our benchmark specification, all else equal. In addition, if the switch involves moving across major task groups, mobility costs are raised further, in ways not captured by the pure distance measure. Yet, despite the considerable role of task content, we find that the largest share of occupation mobility costs are attributable to task-independent entry costs into occupations. These occupation-specific access costs vary widely in size, and are positively correlated with the desirability of any given occupation. Overall, estimated transition costs across occupations are substantial. This finding complements the evidence regarding transition costs across industries in Artuc et al. (2010) and Dix-Carneiro (2014).

The results are robust to alternative ways of characterizing the task content of occupations, using both Dictionary of Occupational Titles and $\mathrm{O}^{*}$ Net data, and hold also when we focus exclusively on the mobility patterns of younger workers.

The model abstracts from the role of occupational tenure in the accumulation of occupationspecific human capital. However Appendix B describes how tenure can be added to this theoretical framework and used in conjunction with longitudinal data sets, if available.

A more substantial and non-trivial extension of the model would entail considering a dynamic setting where workers explicitly maximize a present discounted value of lifetime utility, and some assumption is made about the persistence of the match-quality draws. However, as stressed by Head and Mayer (2013), this is an extension that micro-founded gravity models have yet to address and is an important direction for future work. 


\section{References}

Acemoglu, Daron and David Autor (2011), "Skills, tasks and technologies: Implications for employment and earnings." Handbook of Labor Economics, 4, 1043-1171.

Artuc, Erhan, Shubham Chaudhuri, and John McLaren (2010), "Trade shocks and labor adjustment: A structural empirical approach." American Economic Review, 100, 10081045 .

Autor, David and David Dorn (2009), "This job is "getting old": Measuring changes in job opportunities using occupational age structure." American Economic Review, 99, 45-51.

Autor, David H. and David Dorn (2013), "The growth of low skill service jobs and the polarization of the U.S. labor market." American Economic Review, 103, 1553-1597.

Autor, David H., Lawrence F. Katz, and Melissa S. Kearney (2006), "The polarization of the US labor market." The American Economic Review, 96, 189-194.

Autor, David H., Frank Levy, and Richard J. Murnane (2003), "The skill content of recent technological change: An empirical exploration." Quarterly Journal of Economics, 118, 1279-1333.

Cortes, G.M. (2014), "Where Have the Middle-Wage Workers Gone? A Study of Polarization Using Panel Data." Working Paper.

Dix-Carneiro, Rafael (2014), "Trade liberalization and labor market dynamics." Econometrica, 82, 825-885.

Eaton, J. and S. Kortum (2002), "Technology, geography, and trade." Econometrica, 70, 1741-1779.

Eaton, Jonathan and Samuel Kortum (2001), "Trade in capital goods." European Economic Review, 45, 1195-1235.

Gathmann, Christina and Uta Schönberg (2010), "How general is human capital? A taskbased approach." Journal of Labor Economics, 28, 1-49.

Gervais, Martin, Nir Jaimovich, Henry E Siu, and Yaniv Yedid-Levi (2013), "What should I be when I grow up? Occupations and unemployment over the life cycle." Unpublished manuscript.

Gibbons, Robert, Lawrence F. Katz, Thomas Lemieux, and Daniel Parent (2005), "Comparative advantage, learning, and sectoral wage determination." Journal of Labor Economics, $23,681-724$. 
Goos, Maarten and Alan Manning (2007), "Lousy and lovely jobs: The rising polarization of work in Britain." The Review of Economics and Statistics, 89, 118-133.

Groes, Fane, Philipp Kircher, and Iourii Manovskii (2010), "The U-shapes of occupational mobility." University of Pennsylvania mimeo.

Head, Keith and Thierry Mayer (2013), "Gravity equations: Workhorse, toolkit, and cookbook." CEPR Discussion Paper No. DP9322.

Hsieh, Chang-Tai, Erik Hurst, Charles I Jones, and Peter J Klenow (2013), "The Allocation of Talent and US Economic Growth." National Bureau of Economic Research Working Paper.

ICPSR, 1981 (1981), Dictionary of Occupational Titles (DOT): Part I - Current Population Survey, April 1971, Augmented with DOT Characteristics, and Part II - Fourth Edition Dictionary of DOT Scores for 1970 Census Categories [Computer File]. Study Nr. 07845. National Academy of Sciences - Committee on Occupational Classification and Analysis, Washington DC: U.S. Department of Commerce, Bureau of the Census [Producer], Ann Arbor, MI: Inter-university Consortium for Political and Social Research [Distributor].

ICPSR, 1991 (1991), Dictionary of Occupational Titles (DOT): Revised Fourth Edition, 1991 [Computer file]. Study Nr. 06100. United States Department of Labor, United States Employment Service, and the North Carolina Occupational Analysis Field Center. United States Department of Labor, United States Employment Service, and the North Carolina Occupational Analysis Field Center, Washington, DC: United States Department of Labor, United States Employment Service, and Raleigh, NC: North Carolina Occupational Analysis Field Center [Producer], 1991. Ann Arbor, MI: Inter-university Consortium for Political and Social Research [Distributor], 1994.

Ingram, B.F. and G.R. Neumann (2006), "The returns to skill." Labour Economics, 13, 35-59.

Kambourov, G. and I. Manovskii (2013), "A Cautionary Note on Using (March) CPS and PSID Data to Study Worker Mobility." Macroeconomic Dynamics, 17, 172-194.

Kambourov, Gueorgui and Iourii Manovskii (2008), "Rising occupational and industry mobility in the United States: 1968-1997." International Economic Review, 49, 41-79.

Kambourov, Gueorgui and Iourii Manovskii (2009a), "Occupational mobility and wage inequality." Review of Economic Studies, 76, 731-759.

Kambourov, Gueorgui and Iourii Manovskii (2009b), "Occupational specificity of human capital." International Economic Review, 50, 63-115.

Lazear, Edward P. (2003), "Firm-specific human capital: A skill-weights approach." Working Paper 9679, National Bureau of Economic Research. 
Lemieux, Thomas (2006), "Increasing residual wage inequality: Composition effects, noisy data, or rising demand for skill?" The American Economic Review, 461-498.

Meyer, PB and AM Osborne (2005), "Proposed Category System for 1960-2000 Census Occupations." Bureau of Labor Statistics Working Paper, 383.

Moscarini, Giuseppe and Kaj Thomsson (2007), "Occupational and job mobility in the US." Scandinavian Journal of Economics, 109, 807-836.

Neal, D. (1995), "Industry-specific human capital: Evidence from displaced workers." Journal of Labor Economics, 13, 653-677.

Neal, Derek A (1999), "The complexity of job mobility among young men." Journal of Labor Economics, 17, 237-61.

Nekarda, Christopher J (2009), "A Longitudinal Analysis of the Current Population Survey: Assessing the Cyclical Bias of Geographic Mobility." Federal Reserve Board of Governors.

Parent, D. (2000), "Industry-specific capital and the wage profile: Evidence from the national longitudinal survey of youth and the panel study of income dynamics." Journal of Labor Economics, 18, 306-323.

Peri, G. and C. Sparber (2009), "Task specialization, immigration, and wages." American Economic Journal: Applied Economics, 1, 135-169.

Poletaev, Maxim and Chris Robinson (2008), "Human capital specificity: Evidence from the Dictionary of Occupational Titles and Displaced Worker Surveys, 1984-2000." Journal of Labor Economics, 26, 387-420.

Robinson, Chris (2011), "Occupational mobility, occupation distance and specific human capital." University of Western Ontario, CIBC Centre for Human Capital and Productivity Working Papers.

Shaw, Kathryn L (1984), "A formulation of the earnings function using the concept of occupational investment." Journal of Human Resources, 319-340.

Sullivan, Paul (2010), "Empirical evidence on occupation and industry specific human capital." Labour Economics, 17, 567-580.

Topel, R. (1991), "Specific capital, mobility, and wages: Wages rise with job seniority." Journal of Political Economy, 99, 145. 
Figure 1: Estimates of $S_{j}$ and $-\theta m_{j}$ for the year 2012

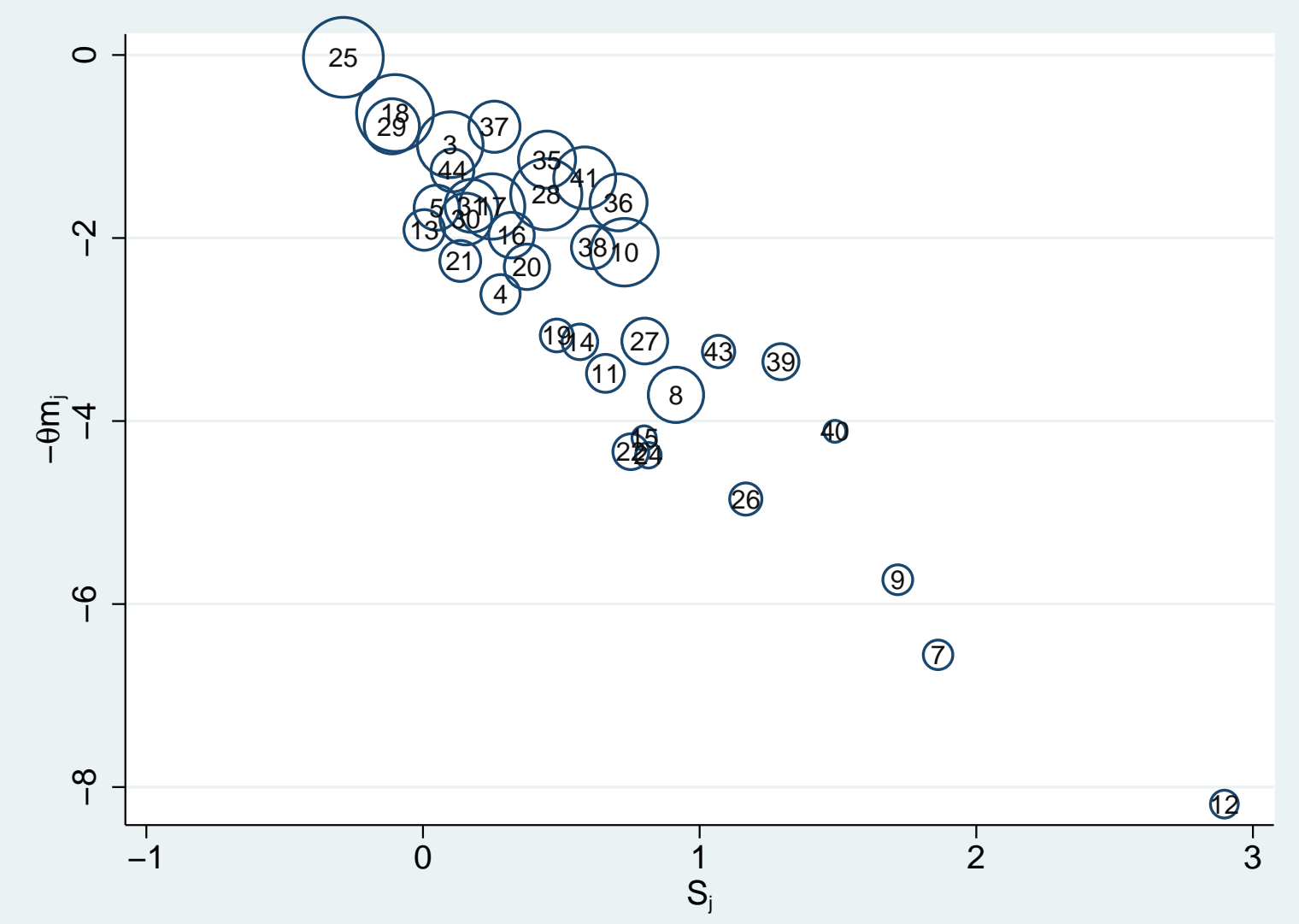

Note: The results are based on the estimated source and destination occupation fixed effects from equation (13). $S_{j}$ is a measure of the attractiveness of occupation $j .-\theta m_{j}$ is related to the general non-task related costs to enter into occupation $j$. Each circle represents a 2-digit occupation, with the size of the circle representing the size of the occupation in 2012, and labeled with its corresponding occupation code; see Appendix Table A.1 for the definitions of each occupation code. 
Table 1: Examples of Task Content

\begin{tabular}{|c|c|c|c|c|}
\hline & $\begin{array}{c}\text { Health Assessment } \\
\text { and Treating }\end{array}$ & $\begin{array}{c}\text { Cleaning and } \\
\text { Building Service }\end{array}$ & $\begin{array}{l}\text { Helpers, Construction } \\
\text { and Production }\end{array}$ & $\begin{array}{l}\text { Freight, Stock and } \\
\text { Material Handlers }\end{array}$ \\
\hline GED-Reasoning & 1.12 & -0.79 & -1.52 & -1.92 \\
\hline GED-Math & 1.08 & -0.59 & -1.24 & -1.42 \\
\hline GED-Language & 1.18 & -0.61 & -1.33 & -1.59 \\
\hline Intelligence & 0.91 & -0.63 & -0.87 & -0.90 \\
\hline Verbal & 0.83 & -0.60 & -0.85 & -0.84 \\
\hline Numerical & 0.57 & -0.57 & -0.82 & -0.91 \\
\hline Spacial & 0.42 & -0.39 & -0.51 & -0.73 \\
\hline Form Perception & 1.07 & -0.63 & -0.68 & -0.83 \\
\hline Clerical & 0.88 & -0.58 & -0.98 & -1.01 \\
\hline Motor Coord & 1.05 & -0.64 & -0.46 & -0.72 \\
\hline Finger Dext & 0.66 & -0.57 & -0.50 & -0.59 \\
\hline Manual Dext & 0.68 & -0.17 & 0.06 & 0.00 \\
\hline Eye-Hand-Foot & -0.05 & 0.23 & -0.04 & -0.30 \\
\hline Color Discrim & 0.56 & -0.34 & -0.54 & -0.73 \\
\hline Distance (DOT) & \multicolumn{2}{|c|}{0.986} & \multicolumn{2}{|c|}{0.004} \\
\hline Distance (ONet) & \multicolumn{2}{|c|}{0.807} & \multicolumn{2}{|c|}{0.062} \\
\hline
\end{tabular}

Note: Each DOT dimension is normalized to have mean zero and standard deviation one across the universe of standardized 3-digit occupations from Autor and Dorn (2013). More details are provided in Appendix A. Distance is calculated as in equation (11). The distance based on $\mathrm{O}^{*}$ Net uses the work activities listed in Appendix Table A.3. 
Table 2: Estimated coefficients on 'gravity-type' equation, 1994-2012

\begin{tabular}{lccc} 
& No Zeros & \multicolumn{2}{c}{ Zeros Replaced } \\
\cline { 2 - 4 } & OLS & OLS & IntReg \\
\cline { 2 - 4 } & $-1)$ & -1.820 & $(3)$ \\
\hline dist & -1.253 & $(.043)^{* * *}$ & -1.950 \\
$\lambda^{N C}$ & $(.026)^{* * *}$ & -.505 & $(.046)^{* * *}$ \\
& -.171 & $(.048)^{* * *}$ & -.579 \\
$\lambda^{R C}$ & $(.029)^{* * *}$ & -.465 & $(.052)^{* * *}$ \\
& -.542 & $(.056)^{* * *}$ & -.424 \\
$\lambda^{R M}$ & $(.032)^{* * *}$ & -1.443 & $(.060)^{* * *}$ \\
& -1.203 & $(.054)^{* * *}$ & -1.472 \\
$\lambda^{N M}$ & $(.031)^{* * *}$ & -.854 & $(.058)^{* * *}$ \\
& -.773 & $(.084)^{* * *}$ & -.850 \\
Const. & $(.048)^{* * *}$ & -3.800 & $(.091)^{* * *}$ \\
& -4.755 & $(.342)^{* * *}$ & -3.620 \\
Obs. & $(.193)^{* * *}$ & 25308 & $(.368)^{* * *}$ \\
$R^{2}$ & 22592 & .527 & 25308 \\
\hline \hline
\end{tabular}

Note: The table presents the results from the estimation of equation (13). Observations are at the occupation pair level. The dependent variable is the normalized flow of workers $\ln \left(s w_{k j} / s w_{k k}\right)_{t}$ at an annual frequency. All specifications include source and destination occupation-year dummies.

Table 3: Summary statistics of estimates of $\underline{\theta}$ and $\theta$

\begin{tabular}{lcc}
\hline Sample: & Full & Restricted \\
Estimate of: & $\underline{\theta}$ & $\theta$ \\
\hline 10th Percentile & 2.202 & 2.462 \\
25th Percentile & 2.455 & 2.792 \\
50th Percentile & 2.887 & 3.229 \\
75th Percentile & 3.173 & 3.736 \\
90th Percentile & 3.421 & 4.288 \\
\hline Mean & 2.843 & 3.321 \\
\hline Nr of Cells & 7,259 & 8,289 \\
\hline \hline
\end{tabular}

Note: The table is based on the distribution of the estimated values of $\underline{\theta}$ and $\theta$ based on the standard deviation of wages as described in Section 4.3. The estimation of $\underline{\theta}$ uses the full sample in each month, by initial occupation, excluding occupation-month cells with less than 100 observations. The estimation of $\theta$ uses a restricted sample of gender-specific demographic bins for those aged 25 to 30 , by month and by initial occupation, excluding cells with less than 15 observations. 
Table 4: Estimated effects on occupational transition costs for each of the specifications in Table 2

\begin{tabular}{lccc|ccc} 
& \multicolumn{3}{c}{ Implied $\widehat{\beta}$} & \multicolumn{3}{c}{ Percentage effect on $d_{k j}$} \\
\cline { 2 - 7 } & No Zeros & \multicolumn{2}{c}{ Zeros Replaced } & No Zeros & \multicolumn{2}{c}{ Zeros Replaced } \\
& OLS & OLS & IntReg & OLS & OLS & IntReg \\
\cline { 2 - 7 } & $(1)$ & $(2)$ & $(3)$ & $(4)$ & $(5)$ & $(6)$ \\
\hline dist & 0.388 & 0.564 & 0.604 & 11.852 & 17.893 & 19.279 \\
$\lambda^{N C}$ & 0.053 & 0.156 & 0.179 & 5.438 & 16.915 & 19.631 \\
$\lambda^{R C}$ & 0.168 & 0.144 & 0.131 & 18.277 & 15.472 & 14.032 \\
$\lambda^{R M}$ & 0.372 & 0.447 & 0.456 & 45.126 & 56.336 & 57.753 \\
$\lambda^{N M}$ & 0.239 & 0.264 & 0.263 & 27.054 & 30.267 & 30.103 \\
\hline \hline
\end{tabular}

Note: Columns (1) to (3) show the marginal effects of distance and the task group switching dummies on the normalized flow of workers across occupation pairs using the estimate of $\theta=3.23$. Columns (4) to (6) show the percentage effect on the transition cost $d_{k j}$ from a one standard deviation increase in distance and from a change from 0 to 1 for the task group switching variables. The standard deviation of distance is computed among the sample of occupation pairs with non-zero flows for the purposes of Column (4) and among the full sample of occupation pairs for the purposes of Columns (5) and (6). 


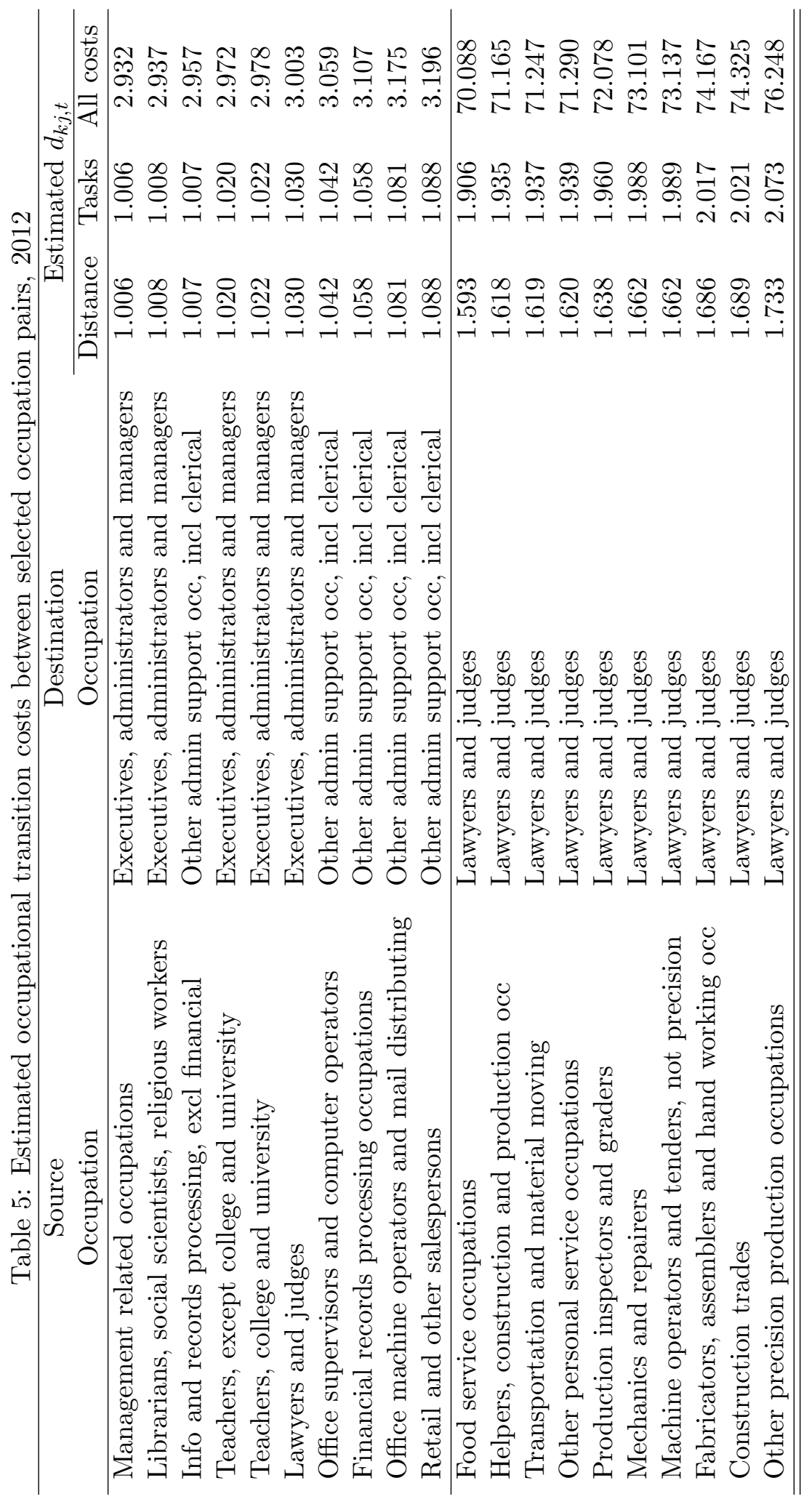


Table 6: Summary statistics for the relative size of the transition cost associated with the task-related variables

\begin{tabular}{lcc}
\hline & Distance & Tasks \\
\cline { 2 - 3 } & $(1)$ & $(2)$ \\
\hline 10th Percentile & 0.005 & 0.010 \\
25th Percentile & 0.015 & 0.028 \\
50th Percentile & 0.031 & 0.056 \\
75th Percentile & 0.051 & 0.097 \\
90th Percentile & 0.081 & 0.131 \\
Maximum & 0.154 & 0.223 \\
\hline Mean & 0.036 & 0.065 \\
\hline Obs. & 25,308 & 25,308 \\
\hline
\end{tabular}

Note: The observations are occupation pair-year cells. Column (1) presents the summary statistics for the fraction of the transition costs that can be attributed to task distance, while Column (2) presents the fraction that can be attributed to all task-related barriers (task distance and costs of transitioning across broad task groups). The remainder is accounted for by task-independent occupational entry costs. 


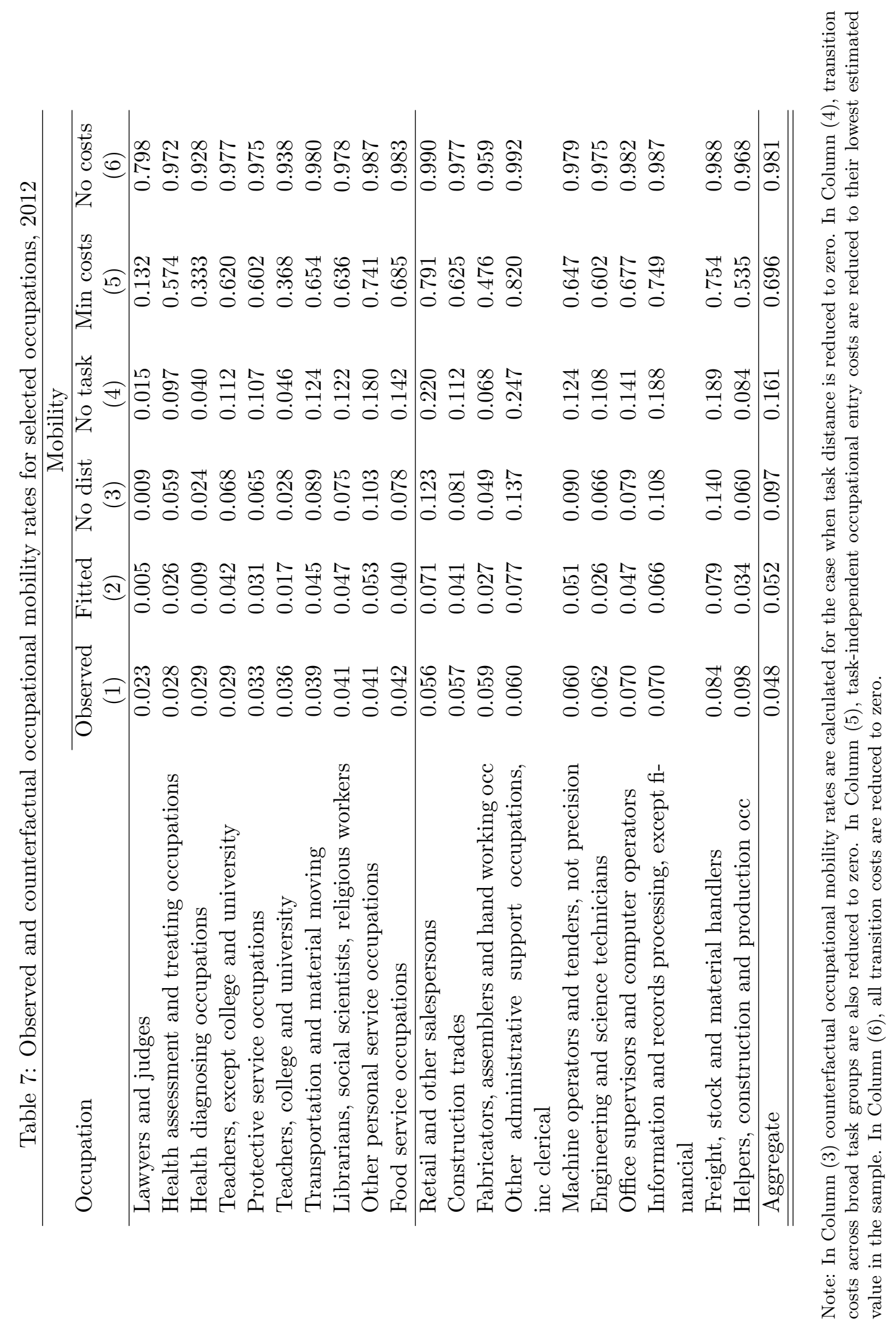


Table 8: Summary statistics for the fraction of the transition costs that can be attributed to task-related variables based on the results from the counterfactual experiments

\begin{tabular}{lcc}
\hline & $\begin{array}{c}\text { Distance } \\
\text { Fraction }\end{array}$ & $\begin{array}{c}\text { Tasks } \\
\text { Fraction }\end{array}$ \\
\cline { 2 - 3 } & $(1)$ & $(2)$ \\
\hline 10th Percentile & 0.031 & 0.077 \\
25th Percentile & 0.043 & 0.097 \\
50th Percentile & 0.054 & 0.125 \\
75th Percentile & 0.067 & 0.156 \\
90th Percentile & 0.078 & 0.181 \\
Maximum & 0.112 & 0.235 \\
\hline Mean & 0.055 & 0.127 \\
\hline Obs. & 703 & 703 \\
\hline \hline
\end{tabular}

Note: The observations are occupation-year cells. Column (1) presents the summary statistics for the fraction of the counterfactual increase in mobility that can be attributed to task distance, while Column (2) presents the fraction that can be attributed to all task-related barriers (task distance and costs of transitioning across broad task groups). The remainder is accounted for by heterogeneity in task-independent occupational entry costs. 


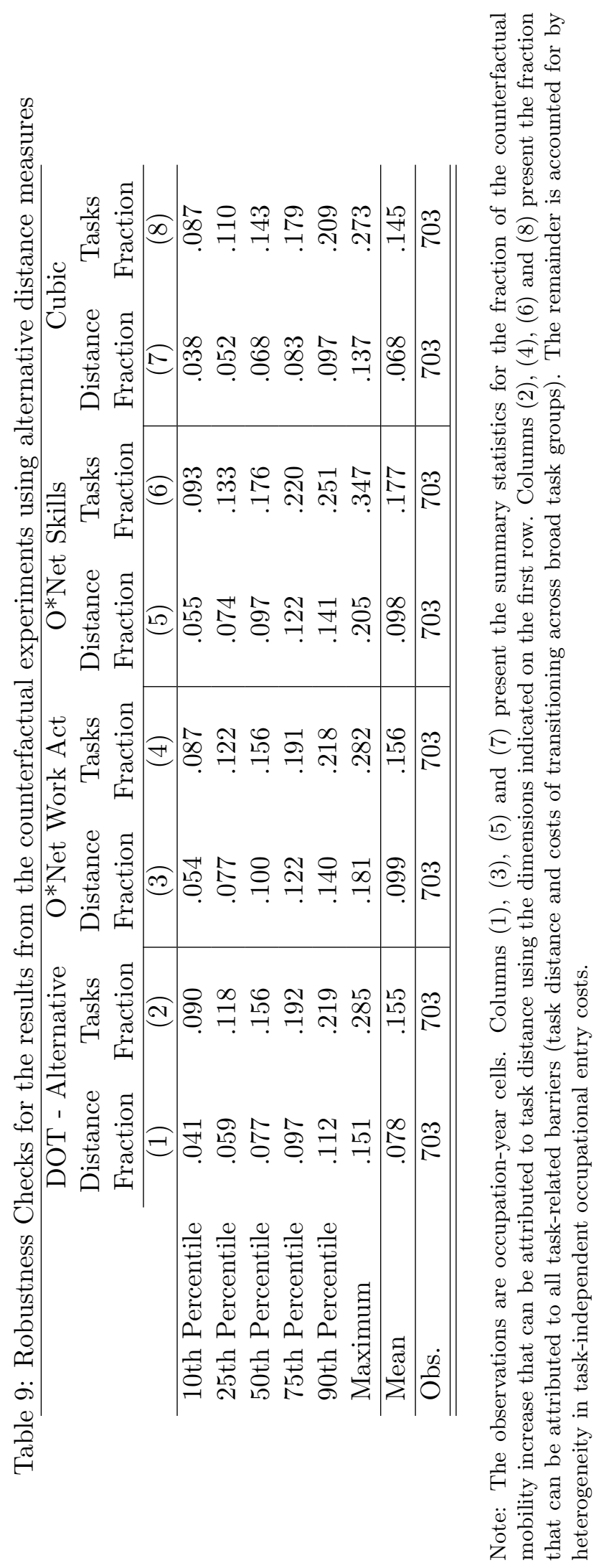


Table 10: Results from the counterfactual experiments using sample of young workers

\begin{tabular}{lcc}
\hline & $\begin{array}{c}\text { Distance } \\
\text { Fraction }\end{array}$ & $\begin{array}{c}\text { Tasks } \\
\text { Fraction }\end{array}$ \\
\cline { 2 - 3 } & $(1)$ & $(2)$ \\
\hline 10th Percentile & .019 & .045 \\
25th Percentile & .030 & .070 \\
50th Percentile & .051 & .118 \\
75th Percentile & .072 & .165 \\
90th Percentile & .088 & .217 \\
Maximum & .172 & .335 \\
\hline Mean & .052 & .123 \\
\hline Obs. & 703 & 703 \\
\hline \hline
\end{tabular}

Note: The observations are occupation-year cells. The results are based on the estimation of Equation (13) using data for younger workers only (aged 18 to 35). Column (1) presents the summary statistics for the fraction of the counterfactual increase in mobility that can be attributed to task distance, while Column (2) presents the fraction that can be attributed to all task-related barriers (task distance and costs of transitioning across broad task groups). The remainder is accounted for by heterogeneity in task-independent occupational entry costs. 


\section{Appendix A Matching DOT with CPS}

The National Crosswalk Service Center provides a crosswalk between the occupation codes in the 1991 Dictionary of Occupational Titles (DOT) and the 1990 Census Occupation Codes (COC). ${ }^{24}$ 1990-COC codes are first converted to the standardized 3-digit occupation codes from Autor and Dorn (2013), which are adapted from Meyer and Osborne (2005). Next, because the DOT classification is much more detailed than the standardized occupation codes, unweighted means are calculated for each DOT dimension at the standardized occupation code level. Each dimension of the DOT is then rescaled to have mean zero and standard deviation one across the universe of standardized occupation codes. Finally, to generate scores at the 2-digit level, an unweighted average is taken across all 3-digit occupations that are within the same 2-digit category.

\section{Appendix B Extension: Occupational Tenure}

This section extends the model to allow for occupation-specific human capital. ${ }^{25}$ Let an individual's tenure in occupation $j$ be denoted $\operatorname{ten}_{j}(i)$, and assume that occupational tenure increases productivity at a rate of $\gamma$ for each additional year of tenure. This leads to the following modified version of Equation (1), where we are explicitly interpreting the potential payoffs in each occupation as wages and therefore denote them as $w_{j}(i \mid k)$ :

$$
w_{j}(i \mid k)=p_{j} f[X(i)]\left(1+\operatorname{ten}_{j}(i)\right)^{\gamma}\left(\frac{z_{j}(i)}{d_{k j}}\right)
$$

The extra productivity from tenure is due to the accumulation of occupation-specific human capital. It is entirely non-transferable and lost when switching out of occupation $j .^{26}$

With this modified wage specification, the probability that occupation $j$ offers individual $i$ the highest wage, which is the probability that individual $i$ will optimally choose to switch to occupation $j$, given his current occupation $k$ (denoted by $\pi_{k j}(i)$ ) is given by:

\footnotetext{
${ }^{24}$ The crosswalk is the National Occupational Information Coordination Committee (NOICC) Master Crosswalk, Version 4.3, downloadable from $\mathrm{ftp}$ ://ftp.xwalkcenter.org/download/xwalks/, file xwalkv43.exe.

${ }^{25}$ For evidence on the importance of occupation-specific human capital, see Kambourov and Manovskii (2009b).

${ }^{26}$ Occupation-specific human capital is assumed to be transferable across employers within the same occupation but is completely lost when switching occupations.
} 


$$
\begin{aligned}
\pi_{k j}(i) & \equiv \operatorname{Pr}\left[w_{j}(i \mid k) \geq \max _{s}\left\{w_{s}(i \mid k)\right\}\right] \\
& =\int_{0}^{\infty} \operatorname{Pr}\left[w_{s}(i \mid k) \leq w, \forall s \neq j\right] \cdot d \operatorname{Pr}\left[w_{j}(i \mid k) \leq w\right] \\
& =\frac{T_{j} d_{k j}^{-\theta}\left[p_{j}\left(1+\operatorname{ten}_{j}(i)\right)^{\gamma}\right]^{\theta}}{\sum_{s=1}^{N} T_{s} d_{k s}^{-\theta}\left[p_{s}\left(1+\operatorname{ten}_{s}(i)\right)^{\gamma}\right]^{\theta}}
\end{aligned}
$$

Note that $\operatorname{ten}_{j}(i)=0 \forall j \neq k$. Therefore, $\forall j \neq k$ :

$$
\pi_{k j}(i)=\frac{T_{j} d_{k j}^{-\theta} p_{j}^{\theta}}{\sum_{s \neq k} T_{s} d_{k s}^{-\theta} p_{s}^{\theta}+T_{k} p_{k}^{\theta}\left(1+\operatorname{ten}_{k}(i)\right)^{\gamma \theta}}
$$

Meanwhile, individual $i$ 's probability of staying in occupation $k, \pi_{k k}$ is given by:

$$
\pi_{k k}(i)=\frac{T_{k} p_{k}^{\theta}\left(1+\operatorname{ten}_{k}(i)\right)^{\gamma \theta}}{\sum_{s \neq k} T_{s} d_{k s}^{-\theta} p_{s}^{\theta}+T_{k} p_{k}^{\theta}\left(1+\operatorname{ten}_{k}(i)\right)^{\gamma \theta}}
$$

Dividing (A.3) by (A.4), and taking logs of the ratio, we have:

$$
\ln \frac{\pi_{k j}(i)}{\pi_{k k}(i)}=\ln T_{j}+\theta \ln p_{j}-\ln T_{k}-\theta \ln p_{k}-\theta \ln d_{k j}-\gamma \theta \ln \left(1+\operatorname{ten}_{k}(i)\right)
$$

Averaging this across individuals in occupation $k$ leads to the gravity-type equation:

$$
\begin{aligned}
\frac{1}{N_{k}} \sum_{i=1}^{N_{k}} \ln \frac{\pi_{k j}(i)}{\pi_{k k}(i)}=\ln T_{j} & +\theta \ln p_{j}-\ln T_{k}-\theta \ln p_{k} \\
& -\theta \ln d_{k j}-\gamma \theta \frac{1}{N_{k}} \sum_{i=1}^{N_{k}} \ln \left(1+\operatorname{ten}_{k}(i)\right)
\end{aligned}
$$

where $N_{k}$ is the number of individuals in occupation $k$.

Note that the right-hand-side of the equation is the same as in the main body of the paper, with the addition of a weighted average of log-tenure in the source occupation. Given that the only individual-specific component on the right-hand-side of the equation is occupational tenure, all individuals with tenure level $x$ have the same transition probabilities. With access to a dataset with a large number of individuals at a number of different tenure levels, the left-hand-side of the equation could be empirically measured as a weighted average:

$$
\sum_{x} \frac{N_{k}^{x}}{N_{k}} \ln \frac{s w_{k j}^{x}}{s w_{k k}^{x}}
$$

where $N_{k}^{x}$ is the number of individuals in occupation $k$ with tenure level $x$ (at the start of the period), $s w_{k j}^{x}$ represents the number of switchers from occupation $k$ to occupation $j$ with 
tenure $x$, and the sum is over the different levels of $x$.

However, it can also be shown that:

$$
\frac{1}{N_{k}} \sum_{i=1}^{N_{k}} \ln \frac{\pi_{k j}(i)}{\pi_{k k}(i)}=\ln \left(\frac{\sum_{i=1}^{N_{k}} \pi_{k j}(i)}{\sum_{i=1}^{N_{k}} \pi_{k k}(i)}\right)+c_{k}
$$

where $c_{k}$ is a constant specific to occupation $k$. Moreover, with a large number of individuals in each occupation we have that:

$$
\ln \left(\frac{\sum_{i=1}^{N_{k}} \pi_{k j}(i)}{\sum_{i=1}^{N_{k}} \pi_{k k}(i)}\right)=\ln \left(\frac{s w_{k j}}{s w_{k k}}\right)
$$

Given (A.8) and (A.9) can rewrite the gravity equation (A.6) as:

$$
\begin{aligned}
\ln \frac{s w_{k j}}{s w_{k k}}=\ln T_{j} & +\theta \ln p_{j}-\ln T_{k}-\theta \ln p_{k}+c_{k} \\
& -\theta \ln d_{k j}-\gamma \theta \frac{1}{N_{k}} \sum_{i=1}^{N_{k}} \ln \left(1+\operatorname{ten}_{k}(i)\right)
\end{aligned}
$$

This can be estimated exactly as in the main text using source and destination occupation fixed effects (interacted with time dummies) and a set of proxies for mobility costs. However, the interpretation of the estimated source occupation fixed effects would change, as they would reflect not only $T_{k}$ and $p_{k}$, but also the adjustment factor $c_{k}$ as well as the effects of occupational tenure. 
Figure A.1: Goodness of fit

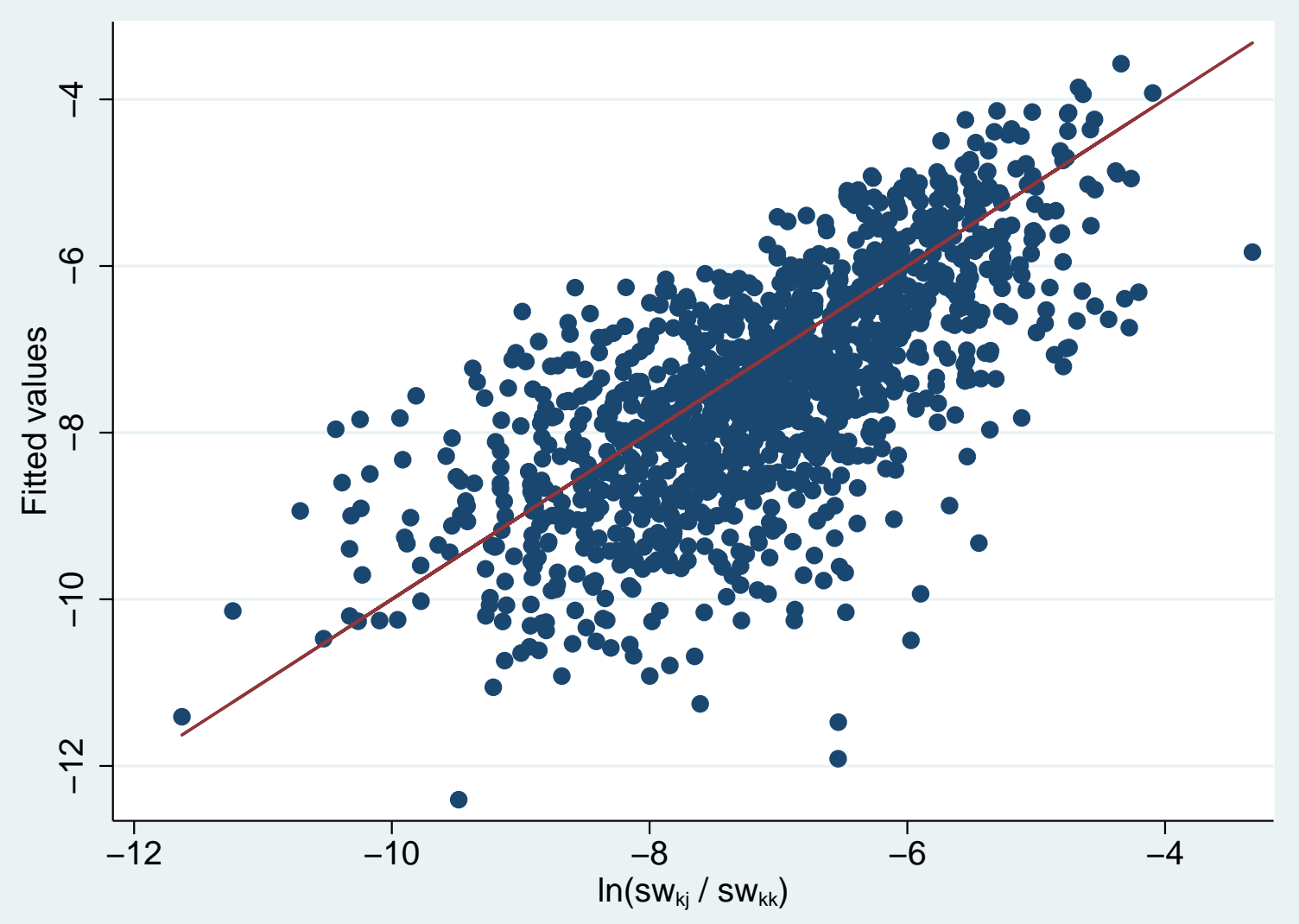

Note: The figure plots the fitted values of the dependent variable $\ln \left(s w_{k j} / s w_{k k}\right)$ against their true values, based on the estimation in Column (3) of Table 2. For visual clarity, the figure includes observations for the year 2012 only. 
Figure A.2: Histogram of estimated values of $\theta$

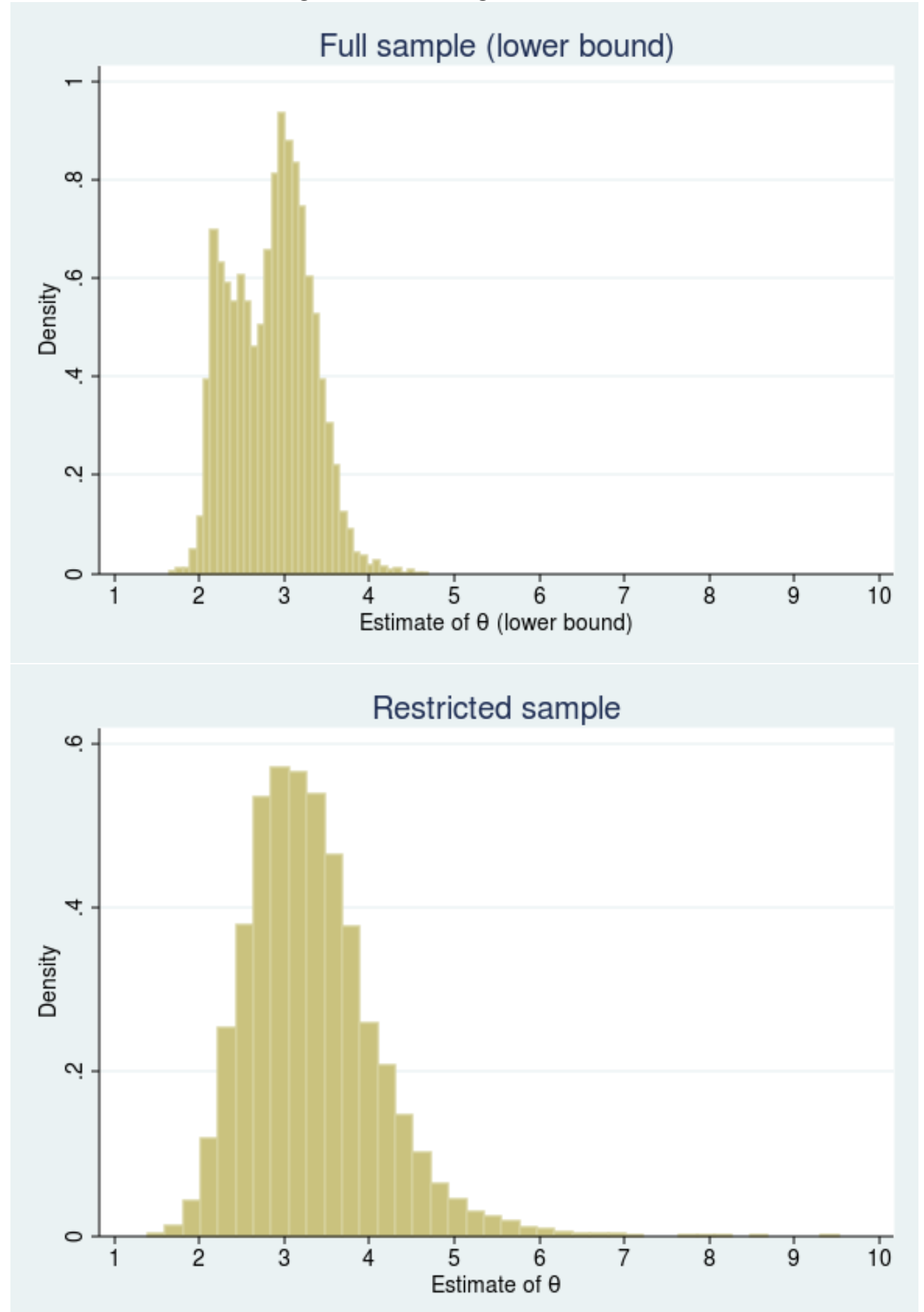

Note: The histogram for the entire sample includes estimated values of $\underline{\theta}$ for each occupation with at least 100 reports. The histogram for the restricted sample includes estimated values of $\theta$ for each gender by initial occupation, restricted to workers aged 25-30, and to groups with at least 15 earnings reports. 
Table A.1: 2-digit occupation groupings for the Autor and Dorn (2013) coding system, organized by task categories

\begin{tabular}{|c|c|c|}
\hline 2-digit Category & 2-digit Code & $\begin{array}{c}\text { 3-digit } \\
\text { Autor and Dorn } \\
\text { Codes }\end{array}$ \\
\hline \multicolumn{3}{|l|}{ Non-Routine Cognitive: } \\
\hline Executives, administrators and managers & 02 & 004-022 \\
\hline Management related occupations & 03 & 023-037 \\
\hline Engineers and architects & 04 & 043-059 \\
\hline Mathematical, computer and natural scientists & 05 & 064-083 \\
\hline Health diagnosing occupations & 07 & 084-089 \\
\hline Health assessment and treating occupations & 08 & 095-106 \\
\hline Teachers, college and university & 09 & 154 \\
\hline Teachers, except college and university & 10 & $155-163$ \\
\hline Librarians, social scientists, religious workers & 11 & $164-177$ \\
\hline Lawyers and judges & 12 & 178 \\
\hline Writers, artists, entertainers, athletes & 13 & 183-199 \\
\hline Health technologists and technicians & 14 & $203-208$ \\
\hline Engineering and science technicians & 15 & $214-225$ \\
\hline Technicians, except health engineering, and science & 16 & $226-235$ \\
\hline Protective service occupations & 27 & $415-427$ \\
\hline \multicolumn{3}{|l|}{ Routine Cognitive: } \\
\hline Sales supervisors and sales reps, finance and business & 17 & $243-256$ \\
\hline Retail and other salespersons & 18 & $258-283$ \\
\hline Office supervisors and computer operators & 19 & $303-308$ \\
\hline Secretaries, stenographers, and typists & 20 & $313-315$ \\
\hline Information and records processing, except financial & 21 & $316-336$ \\
\hline Financial records processing occupations & 22 & $337-344$ \\
\hline Office machine operators and mail distributing & 24 & $346-357$ \\
\hline Other administrative support occupations, including clerical & 25 & 359-389 \\
\hline \multicolumn{3}{|l|}{ Non-Routine Manual: } \\
\hline Private household cleaners and servers & 26 & $405-408$ \\
\hline Food service occupations & 28 & $433-444$ \\
\hline Health service occupations & 29 & $445-447$ \\
\hline Cleaning and building service occupations, except household & 30 & $448-455$ \\
\hline Other personal service occupations & 31 & $457-472$ \\
\hline \multicolumn{3}{|l|}{ Routine Manual: } \\
\hline Mechanics and repairers & 35 & $503-549$ \\
\hline Construction trades & 36 & $558-599$ \\
\hline Other precision production occupations & 37 & 614-699 \\
\hline Machine operators and tenders, not precision & 38 & $703-779$ \\
\hline Fabricators, assemblers and hand working occupations & 39 & $783-789$ \\
\hline Production inspectors and graders & 40 & 799 \\
\hline Transportation and material moving & 41 & $803-859$ \\
\hline Helpers, construction and production occupations & 43 & $865-873$ \\
\hline Freight, stock and material handlers & 44 & $875-889$ \\
\hline
\end{tabular}


Table A.2: Additional Dimensions, DOT 1991

\begin{tabular}{ll}
\hline \hline \multicolumn{1}{c}{ Temperaments: } & \\
Direction, control, or planning & Performing under stress \\
Repetitive work & Deal with set limits, tolerances, standards \\
Influence people & Work under specific instructions \\
Expressing feelings, ideas, facts & Dealing with people beyond instructions \\
Variety of duties, often changing & Judgments and decisions \\
Working alone or in isolation & \\
\hline \hline
\end{tabular}


Table A.3: List of ONet 2009 Work Activities

\begin{tabular}{|c|c|}
\hline 4.A.1.a.1 & Getting Information \\
\hline 4.A.1.a.2 & Monitor Processes, Materials, or Surroundings \\
\hline 4.A.1.b.1 & Identifying Objects, Actions, and Events \\
\hline 4.A.1.b.2 & Inspecting Equipment, Structures, or Material \\
\hline 4.A.1.b.3 & Estimating the Quantifiable Characteristics of Products, Events, or Information \\
\hline 4.A.2.a.1 & Judging the Qualities of Things, Services, or People \\
\hline 4.A.2.a.2 & Processing Information \\
\hline 4.A.2.a.3 & Evaluating Information to Determine Compliance with Standards \\
\hline 4.A.2.a.4 & Analyzing Data or Information \\
\hline 4.A.2.b.1 & Making Decisions and Solving Problems \\
\hline 4.A.2.b.2 & Thinking Creatively \\
\hline 4.A.2.b.3 & Updating and Using Relevant Knowledge \\
\hline 4.A.2.b.4 & Developing Objectives and Strategies \\
\hline 4.A.2.b.5 & Scheduling Work and Activities \\
\hline 4.A.2.b.6 & Organizing, Planning, and Prioritizing Work \\
\hline 4.A.3.a.1 & Performing General Physical Activities \\
\hline 4.A.3.a.2 & Handling and Moving Objects \\
\hline 4.A.3.a.3 & Controlling Machines and Processes \\
\hline 4.A.3.a.4 & Operating Vehicles, Mechanized Devices, or Equipment \\
\hline 4.A.3.b.1 & Interacting With Computers \\
\hline 4.A.3.b.2 & Drafting, Laying Out, and Specifying Technical Devices, Parts, and Equipment \\
\hline 4.A.3.b.4 & Repairing and Maintaining Mechanical Equipment \\
\hline 4.A.3.b.5 & Repairing and Maintaining Electronic Equipment \\
\hline 4.A.3.b.6 & Documenting/Recording Information \\
\hline 4.A.4.a.1 & Interpreting the Meaning of Information for Others \\
\hline 4.A.4.a.2 & Communicating with Supervisors, Peers, or Subordinates \\
\hline 4.A.4.a.3 & Communicating with Persons Outside Organization \\
\hline 4.A.4.a.4 & Establishing and Maintaining Interpersonal Relationships \\
\hline 4.A.4.a.5 & Assisting and Caring for Others \\
\hline 4.A.4.a.6 & Selling or Influencing Others \\
\hline 4.A.4.a.7 & Resolving Conflicts and Negotiating with Others \\
\hline 4.A.4.a.8 & Performing for or Working Directly with the Public \\
\hline 4.A.4.b.1 & Coordinating the Work and Activities of Others \\
\hline 4.A.4.b.2 & Developing and Building Teams \\
\hline 4.A.4.b.3 & Training and Teaching Others \\
\hline 4.A.4.b.4 & Guiding, Directing, and Motivating Subordinates \\
\hline 4.A.4.b.5 & Coaching and Developing Others \\
\hline 4.A.4.b.6 & Provide Consultation and Advice to Others \\
\hline 4.A.4.c.1 & Performing Administrative Activities \\
\hline 4.A.4.c.2 & Staffing Organizational Units \\
\hline 4.A.4.c.3 & Monitoring and Controlling Resources \\
\hline
\end{tabular}


Table A.4: List of ONet 2009 Skills

\begin{tabular}{|c|c|c|c|}
\hline$\overline{\overline{2 . A .1 . a}}$ & Reading Compreh & 2.B.3.b & Technology Design \\
\hline 2.A.1.b & Active Listening & 2.B.3.c & Equipment Selection \\
\hline 2.A.1.c & Writing & 2.B.3.d & Installation \\
\hline 2.A.1.d & Speaking & 2.B.3.e & Programming \\
\hline 2.A.1.e & Mathematics & 2.B.3.g & Operation Monitoring \\
\hline 2.A.1.f & Science & 2.B.3.h & Operation and Control \\
\hline 2.A.2.a & Critical Thinking & 2.B.3.j & Equipment Maintenance \\
\hline 2.A.2.b & Active Learning & 2.B.3.k & Troubleshooting \\
\hline 2.A.2.c & Learning Strategies & 2.B.3.1 & Repairing \\
\hline 2.A.2.d & Monitoring & 2.B.3.m & Quality Control Analysis \\
\hline 2.B.1.a & Social Perceptiveness & 2.B.4.e & Judgment and Decision Mkg \\
\hline 2.B.1.b & Coordination & 2.B.4.g & Systems Analysis \\
\hline 2.B.1.c & Persuasion & 2.B.4.h & Systems Evaluation \\
\hline 2.B.1.d & Negotiation & 2.B.5.a & Time Management \\
\hline 2.B.1.e & Instructing & 2.B.5.b & Mgmnt of Financial Resources \\
\hline 2.B.1.f & Service Orientation & 2.B.5.c & Mgmnt of Material Resources \\
\hline 2.B.2.i & Complex Problem Solv & 2.B.5.d & Mgmnt of Personnel Resources \\
\hline 2.B.3.a & Operations Analysis & & \\
\hline
\end{tabular}

Table A.5: Robustness checks using alternative task dimensions

\begin{tabular}{lcccc} 
& $\begin{array}{c}\text { DOT } \\
\text { Alternative }\end{array}$ & $\begin{array}{c}\text { O*Net } \\
\text { Work Activ }\end{array}$ & $\begin{array}{c}\text { O*Net } \\
\text { Skills }\end{array}$ & $\begin{array}{c}\text { Benchmark } \\
\text { Non-linear }\end{array}$ \\
\cline { 2 - 5 } & $(1)$ & $(2)$ & $(3)$ & $(4)$ \\
\hline$d i s t$ & -2.513 & -2.923 & -2.920 & -3.855 \\
& $(.059)^{* * *}$ & $(.051)^{* * *}$ & $(.049)^{* * *}$ & $(.369)^{* * *}$ \\
$d i s t^{2}$ & & & & 4.704 \\
& & & & $(.871)^{* * *}$ \\
$\lambda^{N C} t^{3}$ & & & -3.113 \\
$\lambda^{R C}$ & -.520 & -.478 & -.922 & $(.591)^{* * *}$ \\
& $(.053)^{* * *}$ & $(.048)^{* * *}$ & $(.044)^{* * *}$ & -.606 \\
$\lambda^{R M}$ & -.593 & -.297 & -.313 & $(.053)^{* * *}$ \\
& $(.060)^{* * *}$ & $(.059)^{* * *}$ & $(.058)^{* * *}$ & -.428 \\
$\lambda^{N M}$ & -1.289 & -.699 & -.556 & $(.064)^{* * * *}$ \\
& $(.059)^{* * *}$ & $(.060)^{* * *}$ & $(.060)^{* * *}$ & -1.478 \\
Const. & -.887 & -.733 & -1.172 & $(.058)^{* * *}$ \\
& $(.090)^{* * *}$ & $(.088)^{* * *}$ & $(.087)^{* * *}$ & -.828 \\
Obs. & -3.361 & -3.232 & -3.146 & $(.091)^{* * *}$ \\
\hline \hline
\end{tabular}

Note: The Table presents the results from the estimation of Equation (13) using alternative task dimensions. The dependent variable is $\ln \left(s w_{k j} / s w_{k k}\right)_{t}$. All specifications include source and destination occupation-year dummies. 
Table A.6: Estimated effects on occupational transition costs for each of the specifications in Table 2 assuming $\theta=4.29$

\begin{tabular}{lccc|ccc} 
& \multicolumn{3}{c}{ Implied $\widehat{\beta}$} & \multicolumn{3}{c}{ Percentage effect on $d_{k j}$} \\
\cline { 2 - 7 } & No Zeros & \multicolumn{2}{c}{ Zeros Replaced } & No Zeros & \multicolumn{2}{c}{ Zeros Replaced } \\
& OLS & OLS & IntReg & OLS & OLS & IntReg \\
\cline { 2 - 7 } & $(1)$ & $(2)$ & $(3)$ & $(4)$ & $(5)$ & $(6)$ \\
\hline dist & 0.292 & 0.424 & 0.455 & 8.799 & 13.195 & 14.196 \\
$\lambda^{N C}$ & 0.040 & 0.118 & 0.135 & 4.068 & 12.488 & 14.449 \\
$\lambda^{R C}$ & 0.126 & 0.108 & 0.099 & 13.473 & 11.440 & 10.392 \\
$\lambda^{R M}$ & 0.280 & 0.336 & 0.343 & 32.369 & 39.996 & 40.951 \\
$\lambda^{N M}$ & 0.180 & 0.199 & 0.198 & 19.756 & 22.030 & 21.914 \\
\hline \hline
\end{tabular}

Note: Columns (4) to (6) show the percentage effect on $d_{k j}$ from a 1 standard deviation increase in distance and from a change from 0 to 1 for the task group switching variables. The standard deviation of distance is computed among the sample of occupation pairs with non-zero flows for the purposes of Column (4) and among the full sample of occupation pairs for the purposes of Columns (5) and (6). 


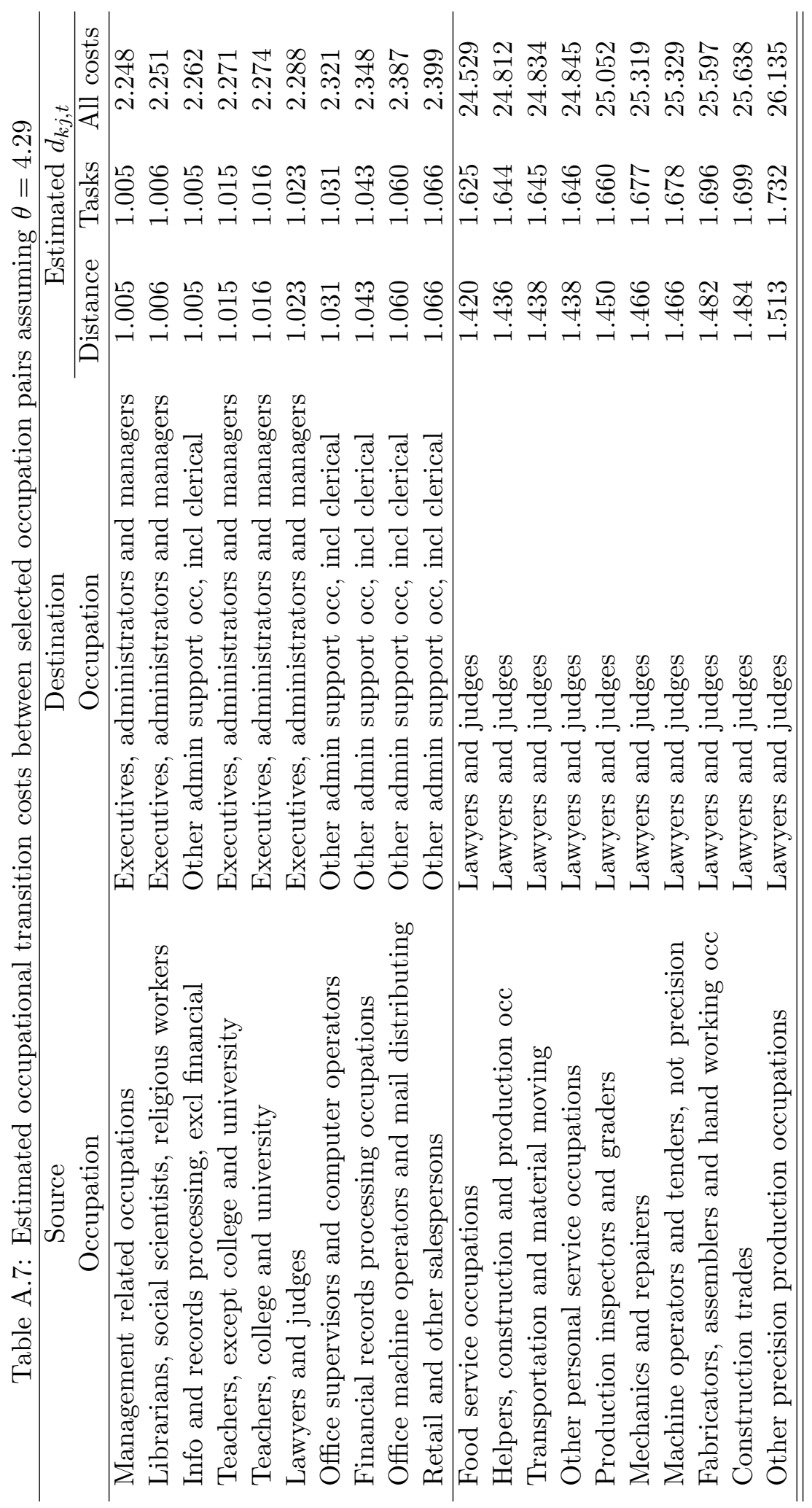

